\title{
A Comprehensive Review of Operation and Control, Maintenance and Lifespan Management, Grid Planning and Design, and Metering in Smart Grids
}

\author{
Luis Hernández-Callejo (i) \\ Department of Agricultural Engineering and Forestry, University of Valladolid (UVA), 42004 Soria, Spain; \\ luis.hernandez.callejo@uva.es; Tel.: +34-975-129-213
}

Received: 24 March 2019; Accepted: 26 April 2019; Published: 29 April 2019

\begin{abstract}
New technological advances based on software, hardware and new materials must be implemented in smart grids. In addition, these advanced electrical grids must incorporate elements of artificial intelligence. Advances in software development must be complemented with the development of new hardware (power electronics and active distribution among others). The aforementioned must rely on the development of new materials and sensors, which should be integrated into the smart grid. Therefore, the four areas of research based on the technologies are: Operation and Control, Maintenance and Lifespan Management, Grid Planning and Design, and Metering. The review presents the algorithms, materials, devices and others paradigms applied to smart grids, classifying the works according to the four areas of research. This review has focused on the four fundamental pillars of smart grids, on the one hand, the need for more efficient operation and control, followed by advanced maintenance management, to continue planning and designing the new grids, and for conclude with the advanced measurement. As you will see in the article, new devices, new techniques, and future scenarios will make possible the transition from the current grid to the future smart grid.
\end{abstract}

Keywords: smart grids; artificial intelligence; smart metering; distributed energy resources; operation and control; maintenance

\section{Introduction}

Electrical grids are changing. We are moving from an "iron and copper" scenario to a more complex grid where developments in electrical engineering and Information and Communication Technologies (ICTs) are dynamically integrated into an automated management system. To achieve this, it is necessary to introduce new equipment into the electrical grid, which should be combined with algorithms and tools (new and traditional). In this context, the smart grid (SG) concept emerges.

The Smart Grids European Technology Platform [1] defines a smart grid as "an electricity network that can intelligently integrate the actions for all users connected to it - generators, consumers and those that do both - in order to efficiently deliver sustainable, economic and secure electricity supplies".

The goal of the Smart Grids European Technology Platform [1] consists in determining longer term research and innovation activities and contributing to the European Union's envisioned $\mathrm{CO}_{2}$ reduction of minimally $80 \%$ by 2050 . In addition to the technological implications, the SG must include social requirements and government commitments. As an example, the U.S. Department of Energy (DOE) [2] and the electricity industry have invested more than 8 billion dollars in this field since 2009 . Some improvements are discussed below: 
- Disturbances can be corrected due to the technologies on the electric transmission system (e.g., using a phasor measurement unit, PMU). This technology allows measurements in real time throughout the entire electrical system.Supply cuts are less frequent, and this is achieved by the implementation of new generation switches and advanced sensors.

- Voltage regulation is being guaranteed within limits by means of new solutions from capacitor banks and other emerging technologies.

- The implementation of Smart Meters (SMs) improves the operation of the electrical system, and provides savings to utilities. SMs are Advanced Metering Infrastructures (AMIs), which allow one to measure, collect and analyze the information of a large number of devices deployed in the electrical infrastructure.

- Customers are served with a better service. In this sense, demand response (DR) can be understood as the change in the use of electricity by consumers. The changes are caused by numerous reasons, the main one being the hourly incentive of the cost of energy.

- Renewable and distributed energy resources (DERs) play a vital role in the SG. The aggregation of small energy sources is DERs, which can be used to satisfy demand or to be associated with renewable systems and storage. Distributed Generation (DG) uses DER, but in points close to consumption, and thus DG breaks with the paradigm of centralized generation.

- New scenarios are appearing in the SG landscape. For example, virtual power plants (VPPs) are an integrated system of DG and DERs to guarantee a reliable supply and maximize the economic benefit. The microgrid is a new paradigm of generation and consumption, where the objective is to guarantee the supply to consumers, but trying to maximize the existing resources in the microgrid.

- Another scale in which VPP and microgrids appear is the smart building concept. Smart buildings are buildings whose equipment and systems (heating, ventilating, air conditioning, lighting, electricity, security, telecommunications, multimedia, computer, access control, etc.) allow management and control (integrated and automated) in order to increase energy efficiency, security, usability and accessibility. To do so, the infrastructure must be upgraded. For instance, buildings should allow the electrical load/unloading of electric vehicles (EVs).

- To achieve efficient and effective operation advanced equipment is needed. The controllers based on microprocessors in the electrical equipment are known as Intelligent Electronic Devices (IEDs). Some examples of these devices are protective relaying devices, load tap changer controllers, circuit breaker controllers, capacitor bank switches, recloser controllers, voltage regulators, etc. However, these devices need to be improved and evolved.

As Peter Vaessen (spokesperson of the DERlab Board DNV GL) explains [3] "We have to move to system verification including not only component testing but also component and system interaction". Mincu (Craciun) Research Coordinator of DERlab adds [3] "The identification of best practices and use cases for laboratory testing of systems and components in a system context is necessary in order to define future testing requirements".

Therefore, it can be said that the new SG will be based on its control elements, the tools that make its operation and maintenance better, better planning and design of existing and future grids, and advanced information from the measure next generation. Considering the above (Smart Grids European Technology Platform, DOE and FutuRed) the four research areas that are the pillars of SGs are presented. These research areas are (Figure 1):

- Operation and Control: the new future grid (SG) must support new elements and developments that allow for more dynamic and advanced operation and control.

- Maintenance and Lifespan Management: the current and future infrastructure must be properly monitored and managed; this will allow advanced maintenance management.

- Grid Planning and Design: the planning of the new future grid must be supported by new advances in planning tools. Thus, the advanced design of new renewable and storage integration scenarios must be undertaken. 
- Metering: moving from iron and copper to the era of communications means having an advanced measure, therefore, it can be said that the $S G$ needs (as a priority) an advance in communication and measurement systems.

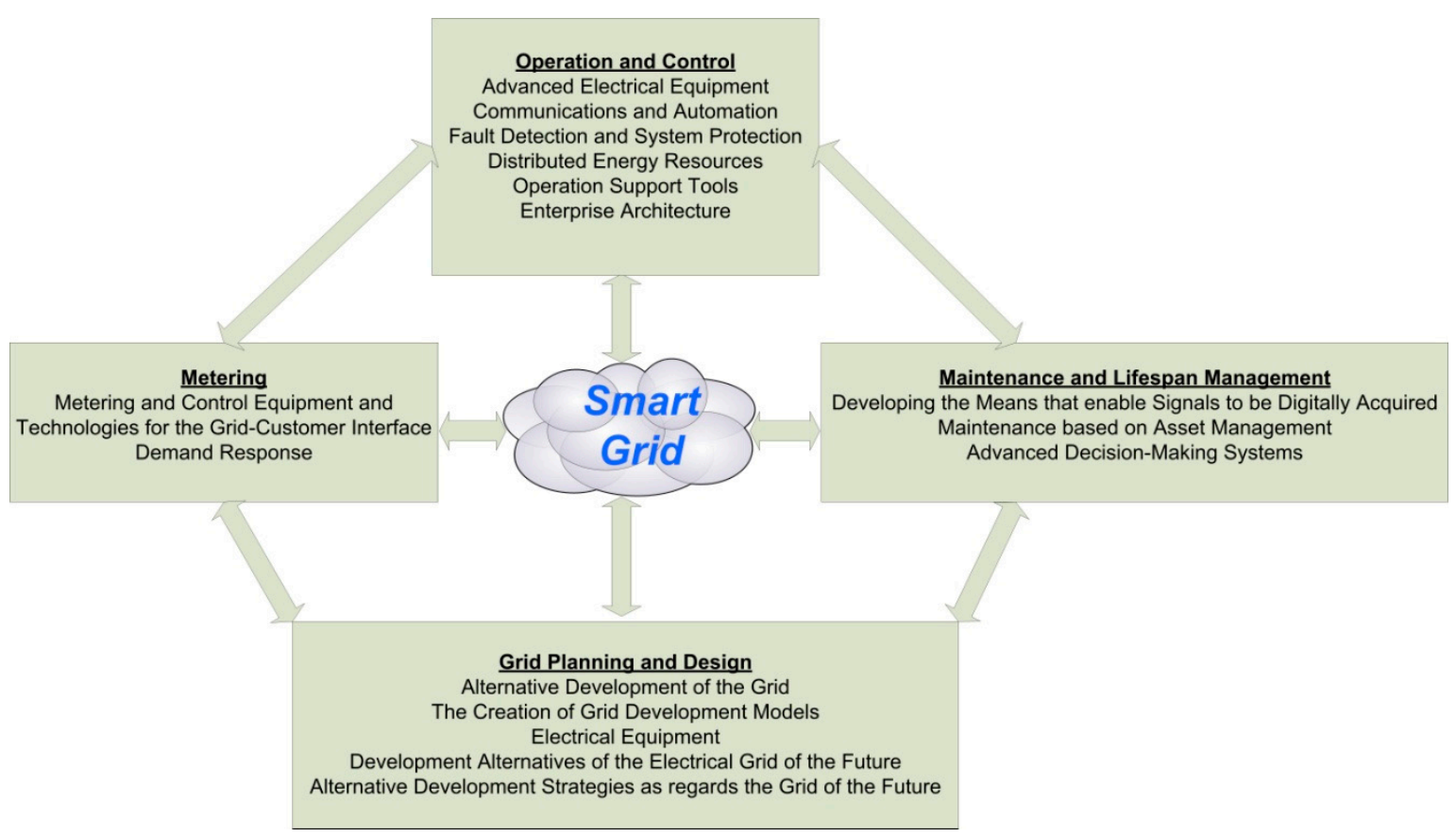

Figure 1. Research areas of SGs. The arrows indicate that all areas are interrelated, since SG can serve information from one area to another.

In order to develop the areas of Figure 1, new technological advances based on software, hardware and new materials must be implemented in the SG. In addition, these advanced electrical grids must incorporate elements of Artificial Intelligence (AI). Advances in software development must be complemented with the development of new hardware (power electronics and active distribution among others). The aforementioned must rely on the development of new materials and sensors, which should be integrated into the SG. Therefore, the four areas of research are based on the technologies shown in Figure 2. Each research area of Figure 1 may belong to one or more of the technologies presented in Figure 2.

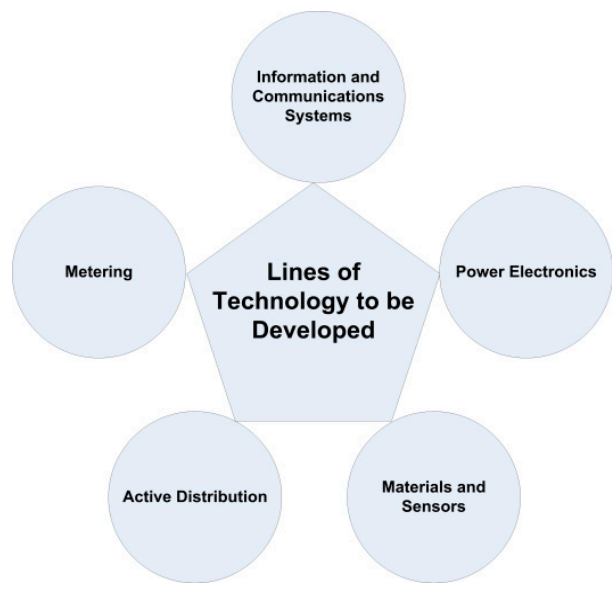

Figure 2. Technology to be developed for research areas of SGs. 
From the explanation in this introduction, the review presents the algorithms, materials, devices and others paradigms applied to SGs, classifying the works according to the four areas of research. According to the author, this classification has been made after a grouping exercise of the works found in recent years. In this work, the author will present 316 scientific works. The review is divided into the following sections: Section 2 shows the work of Operation and Control. In this section we have selected works grouped in the following areas: Advanced Electrical Equipment, Communications and Automation, Fault Detection, Replacement and Quality of Service (QoS), DERs, Operation Support Tools and Connection to the Control System, Integration of Applications; Section 3 presents the works of Maintenance and Lifespan Management. In this section, we have selected works grouped in the following areas: Developing the Means that Enable Signals to be Digitally Acquired, Maintenance based Asset Lifecycle Management and Advanced Decision-Making Systems; Section 4 introduces the work of Grid Planning and Design. In this section we have selected works grouped in the following areas: Alternative Development of the Grid, The Creation of Grid Development Models, Electrical Equipment, Development Alternatives of the Electrical Grid of the Future and Alternative Development Strategies as regards the Grid of the Future; Section 5 details the work of Metering. In this section we have selected works grouped in the following areas: Metering and Control Equipment and Technologies for the Grid-Customer Interface and DR; finally Section 6 presents Discussion and Conclusions.

\section{Operation and Control}

In this scenario (SG), operators need to react with shorter reaction times, since this is the way to guarantee QoS. Thus, the operation and control will be improved. The question is "How will the grid of the future be operated?", therefore, the follwing are necessary:

- Hierarchical operation. Although the medium and high voltage will undergo some changes, the low voltage will be the most affected, since it will operate automatically.

- A greater degree of penetration of renewable energy will help to achieve a sustainable and respectful behavior.

- In a transparent and accessible way with the new agents. The new agents mentioned will be: renewable, advanced sensors, software and hardware improved and new paradigms of electrical grids (microgrids).

- Therefore, the lines of investigation placed in the area of Operation and Control are:

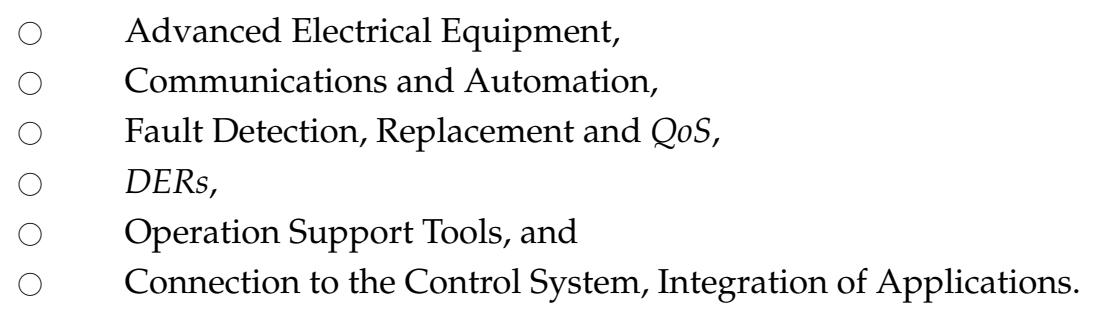

Next, the main contributions in each of the mentioned research lines are presented.

\subsection{Advanced Electrical Equipment}

Equipment with prediction and fault information is interesting, since in this way the operation of the system can be improved. Potential subareas are:

- The field equipment must be updated in a simple way, and the information that it sends must be easily interpretable. Therefore, it is necessary to work on a unified standardization.

- The energy flows must be improved, and in this sense, the new Flexible Alternating Current Transmission System (FACTS) will be necessary.

- As already mentioned, field teams must have elements of self-diagnosis and prediction. 
After the review of the works, the author has considered grouping them in the following subsections: The Improvement, Development and Unification of Electrical Equipment Accessibility Standards, Incorporation of Power Electronics Control Equipment, The Development of Prediction and Self-Diagnosis Systems

\subsubsection{The Improvement, Development and Unification of Electrical Equipment Accessibility Standards}

An important aspect in the SG is the use of interesting variables, and in this way to be able to make efficient management and control. This section presents some outstanding works that take into account the aforementioned.

As Vu et al. [4] show, the utilities should to prevent a local problem from spreading to other parts of the grid. Smart devices processing only local measurements can be counted upon when center-based emergency controls fail to mitigate an aggravating situation.

As O'Driscoll et al. state [5], the classical approach deals with planning using classical metrics. Therefore, these metrics should be revised and expanded. In this regard, energy measurement equipment is critical and fundamental, being able to measure a large number of interesting parameters. This contribution is fundamental for the improvement of the electrical grid.

Standard EN 50160 provides necessary steps to analyses the power quality aspects. However, as shown in Ruiz-Romero et al. [6], DG causes some effects which must be studied, and these effects will be in the control of tension in medium and low tension.

Arai et al. [7] presented the steps in Japan: first, to promote the increase in the penetration of renewable energies; second, to guarantee energy quality through renewable DG; third, improve interconnection from a technological perspective.

\subsubsection{Incorporation of Power Electronics Control Equipment}

The SG, in its natural evolution, must incorporate new equipment. Mainly the SG must integrate power electronics control equipment. This new equipment will perform new actions, or it will use your measured data to serve them to other applications.

The monitoring and control of energy are fundamental according to Kezunovic [8], and due to the proliferation of IEDs in the SG, the data originated by events in the system will trigger the volume of traffic to be managed. It is necessary a new concept, called Translational Knowledge, which comprises: fault locating, alarm processing, and protective relaying. The improvement of the permittivity in the elements of the electrical system is important, and Dervos et al. [9] propose an improvement by means of a cylindrical metal cell.

Some works are based on linear equations or differential equations, which are applied to the information of the equipment. Di Frazio et al. [10] focus on the design, realization and validation of the prototype of an innovative relay (SmartID) based on Kalman. These prototypes are fundamental to achieve the development of the next generation of electrical equipment.

Some authors, such as Zhou et al. [11], consider it of high importance to solve an optimal control in situations of unbalanced voltages for the photovoltaic converters, using differential equations as a solution. As shown by Milanés-Montero et al. [12], the increase in the number of EVs and plug-in hybrid electric vehicles (PHEVs) is inevitable, and this fact will lead to imbalance conditions in the network, so the authors propose a new EV battery charger, based on linear equations and with perfect harmonic cancellation (PHC) in the control.

Zhao et al. [13] analyze the development trend of uninterruptible power supplies (UPS) and they present an intelligent UPS system, where the control employs linear equations for the best solution.

As shown Yang and Gu [14] for a Taiwan Power Company, it is necessary to take into account the trips of switches due to false positives, for which reason they propose linear programming to optimize the coordination between protections.

Yun et al. [15] develop a voltage VAR optimization (VVO) and a complete optimization program in a real environment, which is based on the Sequential Mixed Integer Linear Programming 
(SMILP - mathematical optimization problem where the variables are restricted to integers, the objective function are linear). Continuing with the above, Whang et al. [16] propose a strategy similar to the previous one but for a problem of photovoltaic connection to the grid.

Through the control of VVO it is possible to receive attacks (through the communications layer) In this sense, Majumdar et al. [17] propose an integral solution to mitigate these attacks. The solution combines a controlled adjustment of the voltage regulator and efficient and robust management of communications data.

\subsubsection{The Development of Prediction and Self-Diagnosis Systems}

The SG must also develop and integrate new systems, which will be used for prediction and self-diagnosis. In this section, we will take care of this.

Some works are based on linear estimates and AI. The techniques of AI, and specifically the genetic algorithms, can be used in wind farms, Zhao et al. [18] apply these methods to dampen the reactive power in an induction generator.

As Zeineldin et al. [19] show, DG can include new levels of fault currents, these authors propose a system for its management based on non-linear programming (NLP) system. As is known, AC power transformers have failures at half the rate of high voltage direct current (HVDC) converter transformers, in this sense, Li et al. [20] present a model to evaluate HVDC based on a fuzzy system.

Wang et al. [21] propose an efficient and versatile system for the monitoring and evaluation of overvoltage. The system is used to classify, and it is composed by a fuzzy expert system and a support vector machine (SVM-AI) (similar strategy was used by Jiang et al. [22]). This is an example of AI application for self-diagnosis.

Pasdar and Mehne [23] study the problem of current balancing in a three-phase, to maximize the efficiency of the grid, and they use the "ant colony optimization" method (a probabilistic technique for solving computational problems, within swarm intelligence methods-AI). The authors say that their model improves other existing ones so far.

To summarize, Table 1 shows all the work described in this section. In the rows the types of strategies used (AI, classification, expert systems, etc.) are shown, while in the columns the application rate on the operation and advanced electrical equipment (improvement of electrical equipment, incorporation of power electronics and prediction systems and self-diagnosis) are shown. This section has presented the main works in the area of advanced electrical equipment. The author has detected the existence of numerous works based on AI, classifiers, fuzzy logic, linear systems, systems of differential equations, etc.; therefore, it is interesting to appreciate the interrelation between new electrical equipment and classic and novel techniques of the computational field.

Table 1. Summary of Advanced Electrical Equipment.

\begin{tabular}{cccc}
\hline & \multicolumn{2}{c}{ Operation and Control: Advanced Electrical Equipment } \\
\cline { 2 - 4 } $\begin{array}{c}\text { Summary of Advanced } \\
\text { Electrical Equipment }\end{array}$ & $\begin{array}{c}\text { The Improvement, } \\
\text { Development and } \\
\text { Unification of Electrical } \\
\text { Equipment Accessibility } \\
\text { Standards }\end{array}$ & $\begin{array}{c}\text { The Incorporation of } \\
\text { Power Electronics } \\
\text { Control Equipment }\end{array}$ & $\begin{array}{c}\text { The Development of } \\
\text { Prediction and } \\
\text { Self-Diagnosis Systems }\end{array}$ \\
\hline Classification & {$[9]$} & {$[12,13,16,17]$} & {$[11,15]$} \\
\hline $\begin{array}{c}\text { Linear systems and } \\
\text { differential equations }\end{array}$ & {$[10,14]$} & & {$[23]$} \\
\hline $\begin{array}{c}\text { Expert systems, fuzzy } \\
\text { systems, artificial } \\
\text { intelligence and } \\
\text { nonlinear systems }\end{array}$ & {$[19,20]$} & {$[21,22]$} & \\
\hline $\begin{array}{c}\text { Linear estimator }+ \\
\text { artificial intelligence }\end{array}$ & - & {$[18]$} & - \\
\hline
\end{tabular}




\subsection{Communications and Automation}

Automation and communications must evolve to face the current challenges of the $S G$, as well as future challenges. Potential subareas will be explained:

- The current scenario has a large volume of data through the communications network associated with the SG. Therefore, the communications infrastructure must be robust, secure and reliable.

- The protocols that govern the elements of automation and communication must be standardized. This standardization will allow a better operation and control of the SG.

- The scenario based on big data arises in the SG, since the existence of a large volume of data and heterogeneous, requires the presence of advanced management tools. Big data must conform to the needs of the SG.

After the review of the works, the author has considered grouping them in the following subsections: Advanced Metering Infrastructures, Big Data, Communication Architecture, Standards and Communications Protocols and Automation and Control and New Conditions.

\subsubsection{Advanced Metering Infrastructures}

Basically, bidirectional communication between the utility and the $S M$ is due to the presence of the AMI. The main objective of AMI is to provide data in real time, as well as decision-making by consumers. The first step towards the achievement of an effective AMI is the substitution of the classic energy meters by the SMs. However, the presence of AMI implies a new risk for the SG.

Although there is no single solution, the research projects propose numerous architecture solutions for SG, and all of them supported by AMI, as shown by Ananthavijayan et al. [24]. It is possible to ensure that AMI is the key piece for the development of the SG.

The existence of millions of SM processing information in the AMI, makes this a typological example of a cyber-physical system (CPS). Confidentiality and integrity require a robust encryption system in the keys.

With respect to AMI, Mohassel et al. [25] introduce AMI technology and its current status and its connection with advanced distribution operations (ADO), advanced transmission operations (ATO) and advanced asset management (AAM). Bhatt et al. [26] present AMI, monitoring and automation of substations, power network monitoring, home automation networks (HANs), DR and integration of DG, which have been identified as "Critical Applications". These types of applications are essential for optimal management and control of the infrastructure.

\subsubsection{Big Data}

As it has been commented, an important aspect is the volume of data (Big Data) and his application generated by the SG. Reinhardt et al. [27] use linear equations and IA to eliminate certain characteristic consumption patterns in customer data. Continuing with this, dynamic energy management (DEM) is dependent on the forecast of the renewable production and the load, and these will be based on the data of the SMs, as shown by Diamantoulakis et al. [28]. Therefore, it is possible to affirm that the SG must have tools that allow an advanced data analysis, a high-level computing and advanced techniques for cloud computing.

It is necessary to classify the electric charge, short-term load forecasting (STLF), distributed data mining, dedicated computational grid, cloud data and security. Niyato and Wang [29] present an application of cooperative transmission for the meter data collection in SG based on a non-cooperative game model.

However, big data is important in SG, but it is necessary that the data occupy little space, and for this reason, the compression of the data is fundamental, as shown by Wen et al. [30]. This interconnection between SG and big data must be expanded, and from the interaction, new applications proposals will be developed. 


\subsubsection{Communication Architecture}

The communications systems in the $S G$ will be hybridized (with and without cable). In this sense, it is necessary to have simulators of different technologies, and their interaction with others, so Zhang et al. [31] propose a set of simulation models. This type of tools will allow having a piece of more advanced knowledge about the interaction between technologies and protocols.

The coexistence of clients and distributors in the same domain, through an advanced architecture based on the wide area network (WAN) concept, is exposed in the work of Amhed et al. [32]. The model improves performance parameters, energetic efficiency in data delivery and latency, as in the work of Niyato and Wang [29]. The problem of data collection is addressed through mixed integer linear programming and using cellular networks, as in the case of Li et al. [33].

Another important aspect is the priority in data traffic, such as for control orders, multimedia traffic or reading of meters, and this aspect has been addressed in the work of Huang et al. [34].

An interesting work presented by Allalouf et al. [35] addresses the reduction of the existing data volume, which is based on the reduction of data from different locations.

It is possible to use cloud computing for the development of new solutions for SG, as reported by Markovic et al. [36]. Of all the suggested applications, the efficient storage on a large scale is perhaps the most interesting.

CPS must be integrated into the communications infrastructure and deployed systems. CPS will allow fast and efficient interaction between devices and humans. In short, CPS will affect the SG and it is necessary to contemplate its integration.

The interaction and integration of the physical and cybernetic world enables the Internet of Things (IoT) to be integrated into the SG. Therefore, CPS, IoT and SG must be developed and integrated together. IoT is critical in the SG, since the electrical infrastructure will be completely filled with heterogeneous devices.

\subsubsection{Standards and Communications Protocols}

One of the fundamental pillars that support the intelligence of a SG resides in the capacity of effective management of the information coming from the different equipment and systems that constitute it. For there to be an efficient exchange of information, it is necessary to define communication standards that allow the use of a common language.

The issue of standardization is fundamental, both for groups in Europe and those in the US. The SG has one of its main focuses in the standardization. A key element is the standardization in the electrical network. Already in 1997, Grosmangin [37] considered essential communications standardized architecture. Collaboration between institutions is necessary to address efficient standardization, as proposed by Fan et al. [38]. Standardization is complicated, and we must consider that there are many existing standards, Erlinghagen et al. [39] presented and analyzed 17 standards (wire and wireless). The incompatibility between protocols and architectures has been the consequence of the emergence of efforts by uncoordinated groups, as presented by Albano et al. [40].

It is essential to define standards and communications protocols in SGs. Some works focus on power line communications (PLCd), SG can have a communications solution based on narrow band power line communications (NB-PLC), with an architecture based on IEEE 21451, as presented by Cataliotti et al. [41] and Papadopoulos et al. [42]. This solution enables interoperability, both for intelligent measurement and for protection, control, automation and operation and management.

The protocols must also be updated or improved. In this sense, a new protocol called integrated authentication and confidentiality (IAC) is presented by Yan et al. [43]. It is a protocol that guarantees the confidentiality and integrity of the data.

The standards and protocols based on PLC should be reviewed, as Yigit et al. [44]. Perhaps, the most demanding issue for PLC is to integrate it with internet protocol (IP) or its problems with real time. 
Kulkarni et al. [45] present an overview of some of the candidate solutions and proposes a mesh-radio-based solution, an enhanced version of the routing protocol for LLN (RPL) protocol.

Small scale data exchange can be addressed through Distributed Network Protocol 3.0 over TCP/IP (DNP3 over TCP/IP), as shown in Lu et al. [46]. Another aspect of interest, as shown by Li and Cao [47], is the use of multicast communications and their authentication within the SG.

New performance metrics are needed, in this sense, Zhou et al. [48] present a new metric called accumulated bandwidth distance product (ABDP), which reports on the total of communication resources used in the SG.

Many of the standards presented in the SG (for example, IEC 61850-5) focus on the electrical substation, and the rest of the areas of the SG are forgotten. This is included in the work of Selga et al. [49], and these authors propose a new communication and control architecture focused on low voltage.

Wireless technology presents some practical limitations in an SG scenario. Therefore, and to solve these limitations, Bicen et al. [50] propose a spectrum-aware and cognitive sensor networks (SCSNs), which has a high performance.

In addition, and no less important, semantic interoperability must be addressed. It is very important the ability of computer systems to exchange data, this technique is called semantic interoperability. Semantic interoperability refers to the transfer of data and its meaning, so it is a very interesting concept. The data and its meaning are transported at the same time, so the package is independent of the information system that supports it.

\subsubsection{Automation and Control and New Conditions}

With respect to automation and control, some works focus on advanced protection schemes in last mile networks deployed in direct current, as shown by Abdullah et al. [51]. The monitoring and control depend on the displayed sensor, so the existence of redundancy between the communication nodes is crucial, as Wang et al. [52].

The infrastructure of communications in the field is very interesting, Salvadori et al. (2013) [53] show the benefits of a wired, PLC and wireless architecture. It is possible to have an SG with wired and wireless technology at the same time.

To summarize, Table 2 shows all the work described in this section. In the rows are shown different areas (big data, standardization of protocols and measurement for automation) while in the columns is shown the application rate on communications and automation (mass automation and standardization of communication). As can be seen in the previous table, communications and automation need new protocols, as well as the incorporation of Big Data and new measures to improve automation.

Table 2. Summary of Communications and Automation.

\begin{tabular}{ccc}
\hline \multirow{2}{*}{\begin{tabular}{c} 
Summary of Communications \begin{tabular}{c} 
and Automation \\
\cline { 2 - 3 }
\end{tabular} \\
\cline { 2 - 3 }
\end{tabular}} & $\begin{array}{c}\text { Operation and Control: Communications and Automation } \\
\text { Communications Solutions for } \\
\text { Mass Automation }\end{array}$ & $\begin{array}{c}\text { The Standardization of } \\
\text { Communication with } \\
\text { Automation Elements Protocols }\end{array}$ \\
\hline Big Data & {$[28,33,34,36]$} & {$[27,29,32,35]$} \\
\hline Standardization of protocols & {$[43,48]$} & {$[41,42,44-47,49,50]$} \\
\hline Measurement for Automation & {$[53]$} & {$[51,52]$} \\
\hline
\end{tabular}

\subsection{Fault Detection and System Protection}

In order to improve QoS, it is necessary to locate faults faster so that they can then be isolated. Potential subareas will be explained:

- A key factor is to have intelligent systems for the detection of faults and their subsequent recovery automatically. 
- A second factor has to do with the use of devices for the improvement and quality control of wavelength, in order to give a personal service (from the perspective of quality) to individual consumers.

- Wide Area Monitoring Systems (WAMS)-based area protection systems are necessary. This is necessary because the protection system must also be seen as an extensive network infrastructure, and for this reason, this system can be supported by WAMS.

After the review of the works, the author has considered grouping them in the following subsections: Fault Detection, System Protection and Fault Isolation and System Restoration.

\subsubsection{Fault Detection}

As Bulucea et al. [54] show, the electric connection circuits of power plants require generator circuit-breakers at the generator terminals. Here, the manner in which various factors influence the delay of the zero passing of the short-circuit current is investigated. The work models the main parameters that affect the failures, and perhaps the main parameter is that of the transient recovery voltage.

As Mansson et al. [55] present, the evolution over time of the sources of insecurity must be known, and how the system will be affected.

Sanchez-Sutil et al. [56] study and propose a regulatory framework to frame protection systems. The work focuses on protection systems and grounding devices in direct current circuits, for the feeding of EV charging stations.

Ntalampiras [57] proposes management of the detection of faults by means of Markov chains. Faults are localized by modeling the data to the invariant plane over time. Therefore, the design of new fault detection systems is necessary, and in addition, systems with self-healing will be critical.

\subsubsection{System Protection}

Relating to protection, Yang et al. [58] present a new distributed parameter electrical circuit flashover paradigm of polluted insulators. As Haiyang and Shande [59] define, " ( . . ) adaptive protection is a basic principle of protection, this principle makes the relay can automatically adjust to various protection functions, or changes to more suitable for a given power system conditions ( ... )". The reconfiguration and self-healing of the next generation SG (3G) is addressed in the study by Spitsa et al. (2012) [60].

The anomalies in the wind farms are detected by means of the information acquired through the supervisory control and data acquisition (SCADA) system, as reported by Yang et al. [61]. The parameters of interest are selected by combining the information of the SCADA together with a backpropagation artificial neural network (ANN).

Deshpande et al. [62] offer four main contributions: QoS requirements for SG applications; the authors increase the existing functionalities in differentiated services code points (DSCPs), and they use priority queues for certain critical applications.

\subsubsection{Fault Isolation and System Restoration}

Relating to state estimator, some authors propose a novel algorithm based on information through the PMUs, both at the subsystem level and at the level of coordination of the same. This appears in the work of Yang et al. [63].

As Aminifar et al. [64] show, the significance of predicted and measured data in dynamic state estimation is affected by their confidence levels. The authors present a mixed-integer programming formulation of dynamic state estimation. As Barchi et al. [65] and Barchi et al. [66] show, the work compares the degree of accuracy of four estimators based on synchrophasors, and they are compared with an estimator based on the Fourier transform.

The optimization of the PMU deployment is fundamental for good control and management of the SG, therefore, some works focus on this aspect (Kekatos et al. [67]). In this sense, Gopakumar et al. [68] 
propose a new methodology to classify and identify faults in the distribution and transport lines, and the system is based on the Fourier transform.

Low-frequency disturbances in the distribution network is a topic of interest, therefore, Ma et al. [69] propose an application based on PMU, which reduces the search area of the problem. Coury et al. [70] present a compact genetic algorithm (cGA) based on a field programmable gate array (FPGA) to achieve an efficient estimation of phasors.

As Kim et al. [71] show, SG will be based on WAMS, in order to monitor, analyze and evaluate the instabilities of the system. This communication architecture for control allows efficient and fast management.

Hashiesh et al. [72] propose an intelligent wide area synchrophasor-based system (IWAS) for predicting and mitigating transient instabilities, the system is based on ANN. Ghosh et al. [73] propose a communication link for a complex interconnected power grid, and proper spatial coordination based on geographical information system (GIS) to optimize one of the PMU locations as a main control station.

Robson et al. [74] present a low-cost device for the communication of synchrophasors. The device is supported by frequency modulation together with low-cost hardware, and the results are promising.

To summarize, Table 3 shows all the work described in this section. In the rows are shown different areas (system protection, fault isolation and system restoration) while in the columns is shown the application rate on fault detection and system protection (restoration systems, improvement devices and WAMS-based wide area protection systems). As can be seen in the previous table, fault detection and system protection will use new restoration systems and intelligent fault detection systems; In addition, it will be necessary to develop new devices for quality control and protection systems that work with WAMS.

Table 3. Summary of Fault Detection, Replacement and Quality of Service.

\begin{tabular}{cccc}
\hline $\begin{array}{c}\text { Summary of Fault } \\
\text { Detection, Replacement } \\
\text { and Quality of Service }\end{array}$ & \multicolumn{2}{c}{ Operation and Control: Fault Detection and System Protection } \\
\cline { 2 - 4 } & $\begin{array}{c}\text { Intelligent Fault } \\
\text { Detection and Service } \\
\text { Restoration Systems }\end{array}$ & $\begin{array}{c}\text { Electronic Wavelength } \\
\text { Quality Control and } \\
\text { Improvement Devices }\end{array}$ & $\begin{array}{c}\text { WAMS-Based Wide } \\
\text { Area Protection } \\
\text { Systems }\end{array}$ \\
\hline System Protection & {$[58,59,61]$} & {$[60,74]$} & {$[62]$} \\
\hline $\begin{array}{c}\text { Fault Isolation and } \\
\text { System Restoration }\end{array}$ & {$[57,68-70]$} & {$[65,66]$} & {$[63,64,67,71-73]$} \\
\hline
\end{tabular}

\subsection{Distributed Energy Resources}

Continuing with the above, one of the interests at the global level is to increase the penetration of the $D E R$, so microgrids and the SG will be fundamental. Potential subareas will be explained:

- In order to maintain a stable and secure system, it is necessary to be able to do DR and have microgrids in operation.

- Microgrid projects operating on an island or connected to the distribution grid, and transitions between both states, are necessary. This section includes the microgrid, since the microgrid is a new scenario for DER integration. Section 4.4 presents microgrid works, but from a network improvement perspective and new network designs.

- The evolution of the SG will allow the appearance of new energy services, as well as their management and regulation.

- The integration of DER will simplify the transactions between the different agents, since the generation aggregate will allow direct access to the market.

After the review of the works, the author has considered grouping them in the following subsections: Problems and Challen and Applied Methodologies. 


\subsubsection{Problems and Challenges}

Stuart et al. [75] and Hannon et al. [76] define Energy Service Company (ESCO) as "companies for whom performance-based contracting is a core business activity". ESCOs have DER and storage, and ESCOs will offer new energy services (Plastow, [77]).

The definition of DER is fundamental, since the demand must coincide with the generation. In this sense, Ravindra and Iyer [78] implement a framework for the exact determination of DER. Some works present the improvement in the grid contributing small units of DER (Katiraei, [79], Poudineh and Jamasb [80] and Labanca et al. [81]).

Gouveia et al. [82] propose a new methodology to design and define the energy demand of Portuguese residential users until 2050, concluding that DERs are essential for residential users.

As Weiller and Neely (2014) [83] and Xu et al. (2014) [84] show, new business models appear and in the management of energy for the integration of EVs in electrical systems.

Olivella-Rosell et al. (2018) [85] address the problem associated with DER, and to make the problem more flexible, they formulate a solution based on mixed integer linear programming. It is possible to obtain some conclusions from the previous work, DER brings many benefits to the SG, but in the same way, DER will be the cause of some technical inconveniences that are necessary to solve.

\subsubsection{Applied Methodologies}

Relating to DER management, Shivaie et al. [86] present a distribution layer planning model, and this model uses a self-adaptive global-based harmony search algorithm (SGHSA) model and fuzzy logic.

Logenthiran et al. [87] present a demand-side management strategy based on load shifting technique of future SGs with an evolutionary algorithm (EA).

Some models focus their solution on centralization, while others are based on decentralization. Hassan et al. [88] study this problem in depth, and the authors give different solutions to each scenario.

The penetration of DER and EV can be a problem, the increase of DG and storage will make the power flows are changing, in addition, the increase of EV will require a more robust electrical infrastructure and a greater contribution of energy from renewable. For this reason, Battistelli and Conejo [89] present a complete analysis and a solution to the automation of these scenarios.

Byun et al. [90] propose a smart energy distribution and management system (SEDMS); they use dynamic patterns (autoregressive integrated moving average-ARIMA-model) as controls appliances. The model is valid in a real environment, and the results are very positive.

As Pagani and Aiello [91] show, one of the enabling instruments is the real-time pricing of energy with dynamic and flexible tariffs, helping the power grid to stay in balance; the new services are implemented on service-oriented architecture (SOA).

Ilic [92] proposes a socio-ecological energy system (SEES) framework to improve the functionalities of the system, and the author uses innovative concepts such as: just-in-time (JIT), just-in-place (JIP) and just-in-context (JIC). These concepts come from the industrial world, but the work shows that it is possible to use them optimally in the SG.

Regarding to microgrids and aggregated DER, Houwing et al. [93] present a mathematical model for optimizing aggregate of DER (residential) and micro-CHP. The combination of microgenerators and an optimal management system are fundamental for the deployment of the microgrid.

Giuntoli and Poli [94] present a new algorithm (mixed linear programming), which optimizes your electrical and thermal demand in a VPP. This type of programming allows to communicate with the distributed generators that make up the VPP, and in an optimal way.

Gómez-Sanz et al. [95] present a practical example of microgrid by means of INGENIAS, for which the system is based on multi-agent systems (MAS). The system is fully developed and the results show that it is possible to use MAS for the management and control of a microgrid. 
Oh et al. [96] design a management system for a microgrid, where DR elements are used for emergencies. The model is based on a hardware-in-the-loop simulation (HILS) system, and the authors show that one application of DR is the use of energy for emergencies.

The key to improving building energy efficiency (smart buildings) in operation is to coordinate and optimize the operation of DERs and loads (Guan et al. [97]). Ciabattoni et al. [98] present a high-resolution model (based on fuzzy logic system) of domestic electricity use with photovoltaics systems in smart buildings, and they demonstrate the potential of these techniques in these scenarios.

To summarize, Table 4 shows all the work described in this section. In the rows are shown different areas (problems and challenges and applied methodology) while in the columns is shown the application rate on DER (management, microgrids, new energy services and aggregating DER). As can be seen in the previous table, DER will integrate numerous actors, such as: demand and microgeneration management, microgrids, new energy services and aggregating DER (such as VPP). In all cases, new problems should be addressed, as well as new methodologies should be applied.

Table 4. Summary of Distributed Energy Resources.

\begin{tabular}{ccccc}
\hline \multirow{2}{*}{$\begin{array}{c}\text { Summary of Fault } \\
\text { Detection, } \\
\text { Replacement and } \\
\text { Quality of Service }\end{array}$} & $\begin{array}{c}\text { Demand and } \\
\text { Microgeneration } \\
\text { Management }\end{array}$ & Microgrids & $\begin{array}{c}\text { Operation and Control: Distributed Energy Resources } \\
\text { Technology for the } \\
\text { Incorporation of New } \\
\text { Energy Services }\end{array}$ & $\begin{array}{c}\text { Aggregating } \\
\text { Distributed } \\
\text { Energy Resources }\end{array}$ \\
\hline $\begin{array}{c}\text { Problems and } \\
\text { Challenges }\end{array}$ & {$[75,76,78,82]$} & - & {$[83,84]$} & {$[79-81,85]$} \\
\hline $\begin{array}{c}\text { Applied } \\
\text { Methodology }\end{array}$ & {$[86-88,90,93]$} & {$[95,96]$} & {$[89,91,92,97,98]$} & {$[94]$} \\
\hline
\end{tabular}

\subsection{Operation Support Tools}

The operation and security in the $S G$ require applications, which will serve the system operator. Another need is the improvement of the economic dispatch. Together with the previous one, simulation environments will help decision making. Operators' control centers focus their success on applications with a solid control structure. Potential subareas will be explained:

- $\quad S G$ requires applications capable of working online, and whose objective is to provide the operator with security and obtain an optimized operation. Other aspects of interest are monitoring and forecasting.

- Optimization and simulation tools are essential, and these will be used for medium and long-term decision making.

- The systems and control structure must be $100 \%$ reliable.

The applications of SGs are time-dependent, Foley et al. [99] present the limit time for SGs applications: maximum 1 second for transient stability management and power frequency regulation; maximum one hour for economic dispatch, generation control, power flow, security analysis, fault analysis and voltage stability studies; maximum one week for demand, weather prediction and unit commitment; maximum one months for demand prediction, maintenance planning, hydro planning and fuel planning; and maximum one year for generation expansion planning, reliability checks, scenario analysis and production cost modelling. Gungor et al.) [100] divide the applications for SGs in: consumer side; transport and distribution side; and suppliers side; all the previous sections are dependent on the time to be used by the applications.

After the review of the works, the author has considered grouping them in the following subsections: Agents and MAS, Distortion in the Electrical Grid, Catastrophes in the Electrical Grid and Online Tools and Simulators. 


\subsubsection{Agents and MAS}

In recent years, numerous projects based on MAS have been developed. Despite this, its benefit is not clear and sometimes it is misleading to decide between MAS or a classic alternative.

The aforementioned systems are based on control entities (CEs), which are responsible for the energy trade in local electricity markets (LEMs). The main objective is to maximize a cost function associated with the CE, to subsequently send offers to the LEMs. Subsequently, LEM will send the results of the auction. In other words, CE acts as a seller or buyer of the managed energy. MAS are also used in the control of the network, mainly to guarantee the voltage, frequency and power of the same.

SG presents characteristics of distributed and heterogeneous elements, and this is the main reason that makes using MAS more attractive. The agents that makeup MAS are elements with particular interests, which also fulfill a global function.

The literature presents works based on agents and MAS. Zidan and El-Saadany [101], Xia et al. [102] and Colson and Nehrir [103] propose a MAS to locate and isolate faults, to efficiently predict the system stability and decentralized control architecture for microgrids respectively.

It is possible to use MAS to do distributed control in a microgrid. Nguyen et al. [104] design a system with these characteristics, and the system is validated in a real scenario with positive results. Numerous projects have been developed under the perspective of the MAS. However, it is necessary to understand that not all scenarios are likely to be addressed with MAS.

\subsubsection{Distortion in the Electrical Grid}

The reliability of the system is analyzed by probability in the work of Zou et al. [105]. The study has been validated in distribution feeders, which integrate manageable and non-manageable DG.

Kanevce et al. [106] present a tool to detect vulnerabilities with probabilistic line outages and overloads with direct current load flow and linear programming dispatch of generation. The tool is validated and presents excellent results.

The prediction of faults in distribution sections can be addressed with distribution fault anticipation (DFA) algorithms, as presented by Russell and Benner [107]. This prediction is fundamental to anticipate problems, and the one presented by the authors produces formidable results.

Huang and $\mathrm{Wu}$ [108] formulate and solves the problem of placing additional PMUs into a power grid (based on swarm optimization algorithm). The excess of devices is not beneficial, the authors show that with the exact devices, the results are great.

Some works employ distributed detection schemes, such as the work of Chen et al. [109], which employs a distributed general-anomaly detection (DGAD) scheme. This type of scheme is formulated in a simple way, and its operation helps to keep the grid stable and secure.

Continuing with this, Mahdad and Srairi [110] use an application based on gray wolf optimizer (GWO) mixed with an advanced pattern search, to address the insecurity of the system in SG.

The robustness of the system and the cost of guaranteeing it do not follow a linear relationship, as presented by Huang et al. [111], and this must be taken into account. The authors show that excessive spending is not necessary to maintain a secure electrical grid.

Hong and Chen [112] propose a hybrid system (fuzzy logic and ANN) to detect sources of harmonics in the system. This AI-based detection allows to guarantee stability.

Photovoltaic systems can cause harmonic distractions in the grid, as demonstrated by de Oliveira et al. [113]. These authors propose a new model to characterize the accommodation capacity according to the distortion, and this model is validated in a real environment. It is necessary to take into account the harmonic distortion caused by renewable generation sources.

\subsubsection{Catastrophes in the Electrical Grid}

Relating to catastrophe, disasters caused by electrical parameters in the grid topology are detected by means of a new method, according to Zhen et al. [114]. 
Kamwa et al. [115] build a catastrophe predictor with a tool called wide-area-severity indices (WASI), which is based on random-forest (RF) learning. Following the theme, Hazra and Sinha [116] build a fault sequence detection algorithm, and in this way the algorithm detects the origin of the fault in the system.

Assilzadeh et al. [117] present a model based on GIS where the model includes a monitoring and management system. Ferreira and Barros [118] define a catastrophes detection system based on three algorithms. The first algorithm monitors the nominal value of the current, the second algorithm monitors the value of the energy in each substation and the third algorithm compares the initial and final line current. The system has a direct application and has been validated in a real scenario.

\subsubsection{Online Tools and Simulators}

Regarding to online tools, Biswas et al. [119] design a phasor data simulator and concentrator, which is called the PMU performance analyzer (PPA). In this sense, the authors deliver a simulation tool, which is highly reliable and its use is simple. It is a non-commercial tool, but its development and use are interesting.

Grant et al. [120] and Hernández et al. [121] present online tools for electricity demand forecast based on ANN models, linear models and fuzzy models. They are tailored tools to address a specific problem, the combination in several stages of different techniques allows an interesting solution to the forecasting problem.

The online function of energy management in SG and microgrid is addressed by Siano et al. [122]. The management is done through fully connected neuron (FCN) networks, and its application is optimal for microgrids and SG in general.

The physical behavior of the load can be analyzed using the wavelet transform of the time-frequency domain, as shown by Chang [123]. Subsequently, the author uses this information for energy management. The tool simplifies the operation and is validated in a real environment, and the results demonstrate the suitability of the use of specific tools for management.

The industrial parks are monitored, since the consumption of their energy is important. Therefore, Bruneo et al. [124] propose an online monitoring tool in this type of scenario. The tool monitors all system resources, and interacts with them in a simple and transparent way for the operator.

Arghira et al. [125] present methods for prediction of energy consumption of different appliances in homes; the predictor has two stages, the first is a clustering through k-means, and in a second stage, the prediction is made by cluster. Liao et al. [126] propose a hybrid two-phase online algorithm to put PMUs at selected nodes on the grid and monitor the operating conditions; this simple tool allows to monitor and anticipate problems in the electrical network, and the tool is validated in a real environment.

Regarding simulators, Pillai et al. [127] employ the tool EnergyPLAN, which is used for hourly balanced and aggregate annual analyses of energy. This tool is very powerful, since it allows to simulate different sectorial behaviors (electricity, transport, heating, cooling, etc.). The tool is simple to use and generates a lot of useful reports after the evaluation of the data.

Faria and Vale [128] present DemSi, a DR simulator that allows studying DR actions and schemes in SGs. The tool maximizes market gains through non-linear programming. The maximization takes into account the prices determined for each individual consumer and the price for each type of consumer.

Vallée et al. [129], Flores et al. [130] and Azzopardi and Gabriel-Buenaventura [131] present simulators for prosumers with DER. Prosumer must be taken into account, since its interaction with the market and the system is fundamental, since prosumer will be responsible for changing the flow of energy.

It is also possible to use hybrid methods to the previous ones, and thus simulate the behavior of the market, to obtain information that serves for the regulator or the aggregator. (Shafie-Khan et al. [132]). 
Welsch et al. [133] expand on the open source energy modelling system (OSeMOSYS) simulator, and they describe how blocks of functionality may be added to represent variability in DER, a prioritization of demand types, shifting demand, and storage options. This tool is an open source modeling system, and has already been validated in different electrical scenarios (South America, Africa, etc.).

Yuan et al. [134] expand the integrated resource strategic planning simulator by including the external cost of power plants and cost of efficiency power plants with nonlinear functions. In a similar way, Wang et al. [135] propose an optimized algorithm for the distribution and localization of DER; the algorithm is validated successfully in a real environment.

To summarize, Table 5 shows all the work described in this section. In the rows are shown types of strategies used (agent and MAS, distortion, catastrophes and online tools) while in the columns is shown the application rate on operation support tools (operation control: online and simulation, reliability of the control structure, etc.). As can be seen in the previous table, the operation and control are in need of online and offline process tools. In addition, these tools can be developed under the MAS paradigm, and in some cases, they will be used to detect catastrophes and distortions in the electrical infrastructure.

Table 5. Summary of Operation Support Tools.

\begin{tabular}{|c|c|c|c|}
\hline \multirow[b]{2}{*}{$\begin{array}{l}\text { Summary of Operation } \\
\text { Support Tools }\end{array}$} & \multicolumn{3}{|c|}{ Operation and Control: Operation Support Tools } \\
\hline & $\begin{array}{l}\text { Operation and } \\
\text { Control: Online }\end{array}$ & $\begin{array}{l}\text { Operation and } \\
\text { Control: Simulation }\end{array}$ & $\begin{array}{l}\text { The Reliability of the Control } \\
\text { Structure and the } \\
\text { Characteristics of the Systems }\end{array}$ \\
\hline Agents and MAS & [101-104] & - & - \\
\hline $\begin{array}{l}\text { Distortion in the } \\
\text { Electrical Grid }\end{array}$ & {$[105,109-111]$} & {$[107,108,112,113]$} & [106] \\
\hline $\begin{array}{l}\text { Catastrophes in the } \\
\text { Electrical Grid }\end{array}$ & {$[114,115,117,118]$} & [116] & - \\
\hline $\begin{array}{l}\text { Online Tools and } \\
\text { Simulators }\end{array}$ & [120-124] & {$[119,127-135]$} & {$[125,126]$} \\
\hline
\end{tabular}

\subsection{Enterprise Architecture}

The integration of the information and communication layer of the $S G$ with the other systems of the utility is highly interesting. In this way, the control center achieves a higher added value. Potential subareas will be explained:

- This process requires coordination among all systems, especially those external to the utility. The development of new interfaces between systems is fundamental.

- The databases will begin to increase, therefore, it is necessary to manage them operationally and functionally.

After the review of the works, the author has considered grouping them in the following subsections: Database, Customers and Exchange Between Networks and Technical and Non-Technical Losses.

\subsubsection{Database}

The information coming from remote points is fundamental for correct operation. In addition, this information should travel through the communications layer and stay in a large corporate database (Maass et al. [136]).

Kim et al. [137] uses an IP-based data solution, and in a decentralized manner, in order to obtain a secure, reliable and economically feasible SG.

The identification and classification of consumption profiles is crucial, and in this sense, Werley et al. [138] proposes a clustering method based on c-means and a fuzzy system. To achieve this, the authors perform some preliminary work in the database in order to have the data in the 
best conditions. Therefore, the database takes a fundamental role in the work of pre-filtering and pre-processing of the data in the SG.

The data must be added, since on many occasions the information will come from independent sensors, which will send local and biased information (Lu and Wen [139]). Supervised learning for the improvement of data storage (performance) is advocated by Asensio et al. [140].

It is possible to compare ontologies from the processing of expert systems, as addressed by Santodomingo et al. [141]. Liu et al. [142] present a data model based on three modes: historical, current and future.

Another important aspect is to provide data to test energy management. In this sense, Macedo et al. [143] design a simulation to originate load curve patterns, and this simulator is based on the k-means technique.

\subsubsection{Customers and Exchange Between Networks}

The increase in DG will cause congestion in SG. For this reason, it is necessary to be able to delimit the different levels of access within a grid, and in this way gain in security. In this sense, Angioni et al. (2018) [144] propose a separate and defined architecture.

Relating to customers and exchange between networks, a new communications protocol is presented by Chen et al. (2013) [145], which is based on two-dimensional Markov chain, and its application is for household devices.

Liu et al. (2013) [146] propose a dynamic load control scheme for SG systems based on real-time information of different types of users' consumptions.

Distribution System Operator (DSO) and Independent Power Producers (IPPs) can benefit from a coordinated approach based on a nonlinear constrained optimization problem, and thus offer an auxiliary service for voltage regulation (Calderaro et al. 2015 [147]).

Some authors propose a scenario of interaction between the utility and customers, while guaranteeing QoS and stability (Li and Jayaweera, 2015 [148]).

Distributed data from the Internet are also a subject of study, and Chen et al. (2014) [149] study and evaluate the impact of DR on them.

\subsubsection{Technical and Non-Technical Losses}

Regarding technical losses, Queiroz and Lyra [150] present an adaptive hybrid genetic algorithm and Queiroz et al. [151] raise the parameter called "loss coefficient" to describe the variation of the load and its effect on the estimation of losses.

Relating to non-technical losses, Spiric et al. [152] and Aranha and Coelho [153] present non-technical losses (fraud detection) estimator based on statistics and probability, respectively.

Monedero et al. [154] describe some new advances for the detection of non-technical losses in the customers with a windowed analysis (based on the Pearson coefficient).

Illegal consumers are detected by a procedure based on high performance computing (HPC) algorithms, and this is presented by Shekara et al. [155].

Other authors (Lin et al. [156]) use a non-cooperative model for the detection of non-technical losses, and their accuracy is high.

It is possible to use expert systems to identify non-technical losses, and in this sense, León et al. [157] classify the information of their clients.

The detection of non-technical losses can be addressed with knowledge-based system (KBS) techniques, in conjunction with ANN and other methods, as shown by Guerrero et al. [158].

Continuing with the AI, it is possible to use SVM for the detection of non-technical losses, as they are stated in their work Nagi et al. [159] and Nagi et al. [160].

The detection of non-technical losses and their detection can be accelerated through the use of harmony search algorithm and the optimum-path forest classifier, as reported by Ramos et al. [161]. 
Guerrero et al. [162] propose a non-technical loss detection system in two stages, the first is a filter based on text mining and the second is an ANN. The results are optimal and the frauds are detected.

To summarize, Table 6 shows all the work described in this section. In the rows are shown different areas (database, the exchange between networks and technical and non-technical losses) while in the columns is shown the application rate on enterprise architecture (operation with the external systems and interoperability of large database). As can be seen in the previous table, the interaction of the company with external systems is fundamental, in addition, the interoperability of the databases (with extensive size) is critical for the utility. In this sense, the detection of technical and non-technical losses will be a priority for operators, and the interaction with their customers will be a necessity.

Table 6. Summary of Connection to the Enterprise Architecture.

\begin{tabular}{ccc}
\hline $\begin{array}{c}\text { Summary of Connection to the } \\
\text { Enterprise Architecture }\end{array}$ & \multicolumn{2}{c}{ Operation and Control: Enterprise Architecture } \\
\cline { 2 - 3 } & $\begin{array}{c}\text { Coordinating the Operation with } \\
\text { the External Systems }\end{array}$ & $\begin{array}{c}\text { The Handling and Interoperability of } \\
\text { Large Database }\end{array}$ \\
\hline Database & {$[138,141,142]$} & {$[137,139,140,143]$} \\
\hline $\begin{array}{c}\text { Customers and Exchange } \\
\text { Between Networks }\end{array}$ & {$[145-148]$} & {$[149]$} \\
\hline $\begin{array}{c}\text { Technical and Non-Technical } \\
\text { Losses }\end{array}$ & {$[150-162]$} & - \\
\hline
\end{tabular}

\section{Maintenance and Lifespan Management}

The maintenance of the future in the $S G$ suggests the use of devices with self-diagnosis, and the integration of new digital technologies, which will allow advanced diagnostics. Therefore, the lines of investigation placed in the area of Maintenance and Lifespan Management are:

- Developing the Means that Enable Signals to be Digitally Acquired.

- Maintenance-based Asset Lifecycle Management.

- Advanced Decision-Making Systems.

Next, the main contributions in each of the above mentioned research lines are presented.

\subsection{Developing the Means that Enable Signals to be Digitally Acquired}

The sensors must be integrated into the digital world, and the information generated must be safe and robust. Potential subareas are:

- The self-diagnosis in sensors will allow advanced maintenance, therefore, intelligent sensors are necessary.

- The capture of the data should be more dynamic, which will allow recognizing the problems more exhaustively.

- The anticipation of problem detection suggests the use of monitoring of partial discharges in the electrical lines.

- Development and implementation of the IEC 61850 standard will allow the SG to become digital.

After the review of the works, the author has considered grouping them in the following subsections: Sensors and Parameters, Standardization and normalization and Partial Discharges.

\subsubsection{Sensors and Parameters}

Wang et al. [163] pointed out that the passive optical transformer has excellent measurement quality, in the same way for the active optical transformer. It seems that analog transformers present certain improvements over digital ones, as shown by Kucuksari and Karady [164]; specifically, the output bandwidth in digitals has more limitation than analog ones. 
Li and Wang [165] demonstrate that it is necessary: intelligent transformers, integrative information platform, sequence control, intelligent alarm and smart switches.

It is necessary to have new sensors in the infrastructure, to allow the SG to self-diagnose and self-heal, as presented by Amin [166]. Tang et al. [167] present a partial discharge measurement system using a fluorescent fiber sensor.

Some authors propose the development of a new IED for protections in substations, such as the one presented by Lim and Sidhu [168]. A new fault recognition system is proposed by Kapareliotis et al. [169], and study the signal-to-noise ratio of the electric line. By means of intelligent sensors, it is possible to design a new self-healing strategy, as shown by You et al. [170].

Shen et al. [171] propose a dynamic generator estimator, which is based on certain captured parameters; the method is based on Newton-Raphson. Guo et al. [172] and Ariff et al. [173] present a novel method for estimating parameters based on weighted least squares method and a new approach in estimating important parameters based on Kalman filter, respectively. The new sensors will allow new advances in the development of the SG, and they will also allow the development of new applications based on new monitored variables.

\subsubsection{Standardization and Normalization}

One solution for interoperability is to use IEDs under generic object-oriented substation event (GOOSE) messages, as presented by Clavel et al. [174].

Giustina et al. [175] present the results of communications between automated grids, based on IEC 61850, and the conclusions are that travel times (messages) are less than $40 \mathrm{~ms}$.

It is possible to use a complete and integral model based on IEC 61850, as shown by Zhu et al. [176]. In addition, the monitoring and control of substations can be achieved through IEC 61970 and IEC 61850, as reported by Mercurio et al. [177].

Lee et al. [178] present an approach for unifying data types of IEC 61850 and IEC 61970-301 where authors identify matching, non-matching types and data types.

\subsubsection{Partial Discharges}

The key to the problem of partial discharges is in a good design of the busbar, as recorded by Parent et al. [179]. New developments in busbar are necessary, and their improvement will allow reducing partial discharges.

Relating to partial discharges, Abubakar et al. [180], Boczar et al. [181] and Oyama et al. [182] propose a technique for classifying partial discharge patterns based on ANN.

Cavallini et al. [183] present a methodology for the diagnosis of HVDC systems based on partial discharge analysis with a fuzzy system. Álvarez et al. [184] propose an optimized electromagnetic detection method based on Fourier transform.

It is possible to monitor the partial discharges of networks through direction of arrival (DOA), as presented by Shafiq et al. [185].

There is a certain relationship between the partial discharges and the gas dissolved in the oil, and this is presented in the experimental work of Chen et al. [186]. In addition, the method is based on statistical parameters with canonical correlation analysis.

By means of a chaotic analysis of partial discharges, it is possible to detect certain patterns related to the defects in cable terminals and connection boxes, as presented by Seo et al. [187].

It is possible to obtain a tool for the complete monitoring of defects due to partial discharges, as proposed by Strachan et al. [188]. The system is a decision support system. Bengtsson et al. [189] develop a technique that utilizes the random occurrence of partial discharges for detection and used for semi-square voltages.

To summarize, Table 7 shows all the work described in this section. In the rows are shown different areas (sensors, normalization and partial discharges) while in the columns is shown the application rate on developing the means that enable signals to be digitally acquired (new devices and parameters and 
implementation of the IEC 61850). As can be seen in the previous table, the evolution of sensors and electrical elements will be a reality. In addition, currently shows that these devices should be integrated with IEC 61850. Along with the development of new sensors, it is necessary to define new interesting variables to monitor, since one of the main objectives will be the detection of partial discharges.

Table 7. Summary of Developing the Means that enable Signals to be Digitally Acquired.

\begin{tabular}{ccc}
\hline & $\begin{array}{c}\text { Maintenance and Lifespan Management: Developing the Means that Enable } \\
\text { Signals to be Digitally Acquired }\end{array}$ \\
\cline { 2 - 3 } $\begin{array}{c}\text { Summary of Developing the } \\
\text { Means that enable Signals to be } \\
\text { Digitally Acquired }\end{array}$ & $\begin{array}{c}\text { Optical Digital } \\
\text { Transformers/Intelligence/Capturing } \\
\text { Dynamic Parameters }\end{array}$ & $\begin{array}{c}\text { Development and Implementation } \\
\text { of the IEC 61850 }\end{array}$ \\
\hline Sensors and Parameters & {$[167,169-173]$} & {$[168]$} \\
\hline $\begin{array}{c}\text { Standardization and } \\
\text { normalization }\end{array}$ & - & {$[174-178]$} \\
\hline Partial Discharges & {$[180-189]$} & - \\
\hline
\end{tabular}

\subsection{Maintenance-based Asset Management}

The present and future facilities and infrastructures require advanced maintenance systems that are optimally managed. In this regard, the $S G$ will also need efficient maintenance and asset management systems. Potential subareas are:

- The integrated solutions of $\mathrm{SF}_{6}$ can cause reductions in maintenance costs.

- Out of the substations, there must be standardized communications, therefore, these must be raised.

- To monitor the $S G$ and to optimize the control of assets.

- Tools that allow maintenance based on assets, as well as their management, are necessary.

As Li et al. [190] show, the emphasis should be put on condition monitoring and diagnosis (CMD) devices specific to power transformers, gas-insulated systems, overhead transmission lines and power cables. As Brown and Humphrey [191] show, asset management is a term derived from the financial industry although financial assets are more easily managed than transport and distribution assets, and Prince [192] present the customers as a strategic asset.

After the review of the works, the author has considered grouping them in the following subsections: Asset Management and Monitoring and Maintenance and Risk Management.

\subsubsection{Asset Management and Monitoring}

Regarding to monitoring and assets management, Park et al. [193] present a supervisory monitoring process with an expert system. The monitoring and evaluation of the transformer can be carried out intelligently (with ANN and MAS), as proposed by Ma et al. [194].

Ice flashover faults can be a key factor in grid collapse, Sun et al. [195] model the risk for asset management using SVM, and obtain the model parameters through Bayesian inference.

Dashti and Afsharnia [196] monitor data and analyze it to manage assets in a distribution system.

Ochoa et al. [197] determine the maximum capacity of DG in distribution from a multi-period AC OPF-based technique.

\subsubsection{Maintenance and Risk Management}

Relating to maintenance and risk management, Linares [198], with two risk levels, implements a planning model in an electrical system. Popovic and Popovic (2004) [199] design the methodology to restore electricity supply from the management of diffuse risks. Rocchetta et al. [200] propose an optimal method based on ANN; the authors propose a simple neuronal architecture, where their training has a reduced computational cost. 
Scutariu and Albert [201] propose a mechanism to identify the layout of the sequence of activities for distribution component repair based on statistical techniques. The relationship between preventive and corrective maintenance can be approached from an optimization problem perspective, and its solution can be based on a particle swarm optimization algorithm, as presented by Hilber et al. [202].

Interesting work is the one presented by Yumbe et al. [203], the authors define a complete program to inspect distribution facilities and optimally; the method is based on a complex algorithm. The algorithm is based on two sections: estimation of inspection interval and optimal schedule generation. The algorithm manages to reduce the cost of inspection by $14 \%$, and also guarantees the stability of the system.

By means of a laser monitoring, it is possible to perform the maintenance of distribution lines, as presented by Tajnsek et al. [204]. These data are crossed checked with GIS and control information.

Yang et al. [205] present a novel maintenance program from decision-varying Markov models, and Heo et al. [206] combine Markov with a modified genetic algorithm.

To summarize, Table 8 shows all the work described in this section. In the rows are shown different areas (asset management and risk management) while in the columns is shown the application rate on maintenance based on asset lifecycle management. As can be seen in the previous table, maintenance and asset management is reinforced by AI and other simpler techniques. Therefore, these management tasks will be essential for operators, and the use of advanced techniques essential for its implementation and use.

Table 8. Summary of Maintenance based on Asset Lifecycle Management.

\begin{tabular}{ccc}
\hline \multirow{2}{*}{$\begin{array}{c}\text { Summary of Maintenance Based } \\
\text { on Asset Lifecycle Management }\end{array}$} & \multicolumn{2}{c}{$\begin{array}{c}\text { Maintenance and Lifespan Management: Maintenance } \\
\text { Based on Asset Lifecycle Management }\end{array}$} \\
\cline { 2 - 3 } & Artificial Intelligence & Other Techniques \\
\hline $\begin{array}{c}\text { Asset Management and } \\
\text { Monitoring }\end{array}$ & {$[193-195]$} & {$[196,197]$} \\
\hline $\begin{array}{c}\text { Maintenance and Risk } \\
\text { Management }\end{array}$ & {$[199,200,206]$} & {$[198,201,205]$} \\
\hline
\end{tabular}

\subsection{Advanced Decision-Making Systems}

From the above, it is interesting to have tools for decision making. In this way, the decision-making process can be automated. Potential subareas will be explained:

- An intelligent decision-Making system in the $S G$ is necessary. In this regard, it is possible to use an advanced engine, and apply it directly to maintenance and asset management.

- Maintenance models based on the expert systems and other systems in the SGs are required.

After the review of the works, the author has considered grouping them in the following subsections: Power System Infrastructure, DER, DR and Efficiency Energy and Multiple Criteria Decision Making.

\subsubsection{Power System Infrastructure}

AI has been used continuously for a great amount of time, as reported by Madan and Bollinger [207]. Therefore, and following with Burt et al. [208], expert systems can serve for maintenance and decision making, since they can learn from the alarms received. In this sense, Mohagheghi [209] uses expert systems to detect vulnerabilities in automated systems, which allows a more efficient and controlled system.

It is possible to detect variations in the network from the data received using symbolic aggregate approximation (SAX) and pattern recognition, as defined by Alam et al.) [210]. Jimenez et al. [211] implement an S-transform algorithm for the detection and monitoring of overvoltage. 


\subsubsection{DER, DR and Efficiency Energy}

Radhakrishnan and Srinivasan [212] present a MAS-based distributed SEDMS to perform optimal energy allocation and management for grids comprising of DER, storage and DG. By controlling the state of charge $(\mathrm{SoC})$ of storage it is possible to guarantee a balance in power. All control is done through a fuzzy system.

As Sianaki et al. [213] shown, DR is possible at the household level, so they define an intelligent algorithm for correct decision-making aimed at achieving DR.

In many countries, specifically in the United States, the relationship between season and peak demand is different between sectors (residential, commercial and industrial (C\&I), etc.), and this is analyzed by Liu [214].

Gellings and Samotyj [215] focus on which of those SG functionalities are going to facilitate the ever-growing need for enhanced DR and load control.

Janjic et al. [216] propose four criteria for the decision making of seven actions in a SG. The authors use a method based on fuzzy AHP multi-criteria for the improvement of energy efficiency.

\subsubsection{Multiple Criteria Decision Making}

Decision making is a totally interactive task, so the current data is critical. Bidirectionality in information is fundamental, and in this sense, fuzzy logic can help decision-making, as Pedrycz and Chen [217] have shown.

The criteria that affect electricity supply are basically social, environmental, technical and economic, as reported by Wang et al. [218]. Numerous techniques are used under the umbrella of multiple criteria decision making (MCDM), but blurred logic always appears.

Complex scenarios can give optimal results if MCDM is used. In this sense, MCDM is highly employed in the electrical system, since the results are very positive. Kumar et al. [219] consider that MCDM can support the integration of renewable generation sources. The classification of MCDM is: multi-objective decision making (MODM), multi-attribute decision making (MADM) and combinations of MODM and MADM. Further, the multi-criteria decision models are: elimination and choice translating reality (ELECTRE) group, preference ranking organization method for enrichment evaluation (PROMETHEE), simple additive weighting (SAW), analytic hierarchy process (AHP), multi-attribute utility theory (MAUT), novel approach to imprecise assessment and decision environment (NAIADE), and stochastic multi-objective acceptability analysis (SMAA).

Mondal et al. [220] design an architecture of interactions between customers and the utility. The defined programming is based on finding a solution to two problems, centralized sequential decision making with hidden model Markov decision process (HM-MDP) at the controller to maximize an accumulated reward for the whole microgrid.

The decision making must be based on the monitoring of the system. Ansari et al. [221] present a novel approach to the decentralized optimal reactive power control (DORPC) problem based on a holonic architecture. The approach is approached with MAS.

Some authors optimize the installation from a techno-economic perspective, as in the case of Shadmand and Balog [222]. The presented model is based on a multi-objective genetic algorithm (MOGA).

Janjic et al. [223] use a methodology based on fuzzy logic, and the authors take into account qualitative and quantitative criteria, as well as varied performance indicators in the SG.

It is interesting to obtain new island detection algorithms, for example, Laaksonen [224] implement a new multi-criteria based island detection algorithm.

In photovoltaic systems, decision-making criteria have always been economic. In this sense, Matulaitis et al. [225] propose a new multi-criteria framework to evaluate the financial support of small-power photovoltaic plants.

Related to intelligent decision-making, Padhee et al. [226] present a new fast Gauss-Newton algorithm for the detection of islanding condition in DGs systems. 
Pouresmaeil et al. [227] develop a novel technique for flexible interconnection of DG resources to distribution grids. The technique is successful and augurs great application success.

A new decision-making model based on stochastic programming is implemented by $\mathrm{Oh}$ and Hildreth [228].

The frequency estimation of signals in the electrical system can be obtained by means of a genetic algorithm, as developed by Coury et al. [229].

To summarize, Table 9 shows all the work described in this section. In the rows are shown different areas (infrastructure, DER and similar and intelligent decision-making) while in the columns is shown the application rate on advanced decision-making (AI and other techniques). As can be seen in the previous table, advanced decision-making is essential for the energy infrastructure (generation), DER, DR and advanced decision-making systems. For this, these mechanisms may be based on AI and other simpler techniques.

Table 9. Summary of Advanced Decision-Making Systems.

\begin{tabular}{|c|c|c|}
\hline \multirow{2}{*}{$\begin{array}{l}\text { Summary of Maintenance Based } \\
\text { on Asset Lifecycle Management }\end{array}$} & \multicolumn{2}{|c|}{$\begin{array}{c}\text { Maintenance and Lifespan Management: Advanced } \\
\text { Decision-Making }\end{array}$} \\
\hline & Artificial Intelligence & Other Techniques \\
\hline Power System Infrastructure & [209] & {$[210,211]$} \\
\hline DER, DR and Efficiency Energy & {$[212,216]$} & [213-215] \\
\hline Intelligent Decision-Making & {$[217,221-223,229]$} & {$[218-220,224-228]$} \\
\hline
\end{tabular}

\section{Grid Planning and Design}

It is possible to define the main challenges of SG 2035, namely: the network infrastructure is complicated to expand; the new generation plants are difficult to locate in advance; the penetration level of DG will increase; and the environment is increasingly important.

The increased penetration of the DG is a great challenge, despite its great benefits. On some occasions, the installation of DG will be in spaces with low consumption, so the grid infrastructure will be insufficient. The protection measures must evolve in order to receive the DG.

To achieve this flexibility in the network, some solutions have been proposed, namely:

- Improvement in the evacuation capacity of drivers.

- The power flows must be controlled through FACTS.

- Have predictive tools that locate the new plants to be deployed.

- Improvement in the tools for predicting demand and production.

- The management of the DG should be regulated.

- Distribution networks should reach levels similar to those of transport. The stretches of tension in distribution must be greater, and in addition, the number of these must increase. In this way, DG can penetrate more easily.

Therefore, the lines of investigation placed in the area of Grid Planning and Design are:

- Alternative Development of the Grid.

- The Creation of Grid Development Models.

- Electrical Equipment.

- Development Alternatives of the Electrical Grid of the Future.

- Alternative Development Strategies as regards the Grid of the Future. 


\subsection{Alternative Development of the Grid}

The society is showing a clear rejection of the installation of new electricity grid infrastructures, making it difficult to install new power lines. However, the progressive penetration of the DG makes necessary the installation of new infrastructures. Potential subareas will be explained:

- Substations and power lines should not cause so much impact (social and environmental). The tendency is not to extend the mileage of power lines.

- It is necessary to have new conductors, especially conductors that work well at high temperatures.

After the review of the works, the author has considered grouping them in the following subsections: Cables and High Temperature Superconducting, FACTS and Lines and Substations.

\subsubsection{Cables and High Temperature Superconducting}

As Zhang et al. [230] show, the substation of the future integrates a high temperature superconducting (HTS) power cable, a HTS transformer, a HTS fault current limiter and a high-Tc superconducting magnetic energy storage devices.

Regarding cables and high temperature, the problem in SGs can be solved more efficiently by using the latest generation HTS cables (Geschiere et al. [231]), these are smart cables, which have a smoothed tension profile in normal operation.

HTS cable is one of important apparatus in future SG, Wang et al. [232] adjust the inductive reactance, so they manage to minimize the losses. One of the advantages of HTS cables is their small volume, high current density, low losses and high transport capacity, as shown by Pi et al. [233]. These authors develop new insulation for $10 \mathrm{kV}$ HTS cables, and the results are very good.

\subsubsection{FACTS}

Relating to FACTS, Xiao et al. [234] propose a new FACTS with maximum power transfer. Cvetkovic and Ilic [235] achieve transient stability with a new FACTS model, which uses a nonlinear model on the shape of the differential equation. Lashkar et al. [236] develop a new methodology to locate exactly the installation of FACTS shunt-series controllers.

HVDC and FACTS are controlled by fuzzy systems with very good results (Ramesh et al. [237]). Ghahremani and Kamwa [238] present a graphical user interface based on a genetic algorithm, to easily locate the FACTS. However, Tuzikova et al. [239] use particle swarm optimization to reduce losses in the FACTS.

\subsubsection{Lines and Substations}

Relating to new designs of lines and substations, Ravadanegh and Roshanagh [240] propose the application of an imperialist competitive algorithm (ICA - a genetic algorithm), which optimizes the expansion of a distribution network.

Leborgne et al. [241] present a method based on voltage drop to evaluate the performance of power lines.

Salmerón and Vazquez [242] present a new active powerline conditioners control design based on ANNs for new lines.

It is necessary to replicate the voltage instability, and Corsi and Pozzi [243] propose an analysis to reconstruct said phenomena.

Based on a mixed integer linear programming problem it is possible to propose a substation planning model, as done by El-Fouly et al. [244].

It is also necessary to optimally organize transformers in low voltage, Esmaeeli et al. [245] propose a novel system to do so.

Through the new model of Akbari et al. [246], it is possible to minimize the investment and operating costs of the electric substations. 
Kabir and Sumi [247] develop a simple, systematic and logical scientific approach to evaluating power substation location based on fuzzy process, similar to Khoshsolat et al. [248].

Wang et al. [249] present a method to classify the substations into several classes, and for which it classifies the characteristics of the load from a self-organization map (SOM).

To summarize, Table 10 shows all the work described in this section. In the rows are shown different areas (cables and HTS, FACTS, lines and substations) while in the columns is shown the application rate on electrical equipment (AI and other techniques). As can be seen in the previous table, the development of new electricity infrastructure scenarios is necessary; in this sense, improved substations, new cables will be developed. Again, these developments are being addressed through AI and other simpler techniques.

Table 10. Summary of Alternative Development of the Grid.

\begin{tabular}{ccc}
\hline \multirow{2}{*}{$\begin{array}{c}\text { Summary of Maintenance Based } \\
\text { on Asset Lifecycle Management }\end{array}$} & Grid Planning and Design: Alternative Development of the Grid \\
\cline { 2 - 3 } & Artificial Intelligence & Other Techniques \\
\hline Cables and HTS & - & {$[230-233]$} \\
\hline FACTS & {$[237-239]$} & {$[234-236]$} \\
\hline Lines and Substations & {$[240,242,247-249]$} & {$[241,243-246]$} \\
\hline
\end{tabular}

\subsection{The Creation of Grid Development Models}

The $S G$ faces the uncertainty of the deployment of $D G$, increase in electricity demand and the commissioning (or not) of new electricity infrastructures. Potential subareas are:

- The location of the generation plants should be estimated.

- The integration of renewable generation sources will be aided by energy storage.

Electrical storage must be improved and integrated into the SG. In this sense, Rodrigues et al. [250] analyze the current and future situation of energy storage, concluding that the storage of energy is the key for the SG. It is important to consider all technologies, as Adhau et al. [251] show, micro hydropower plants are emerging as a major renewable energy/storage resources and the water after generating electrical power is available for irrigation and others purposes. After the review of the works, the author has considered grouping them in the following subsections: Tools for Generating Plants and Storage Energy and Energy Storage.

\subsubsection{Tools for Generating Plants and Storage Energy}

Relating to tools for generating plants and storage energy, Payyala and Green [252] propose an economic assessment of a power plant, but an optimal plant can be a cause of voltage, current, etc. failures.

Cornalino et al. [253] present a simulator of DER with a stochastic model with Gaussian space correlations (GSPs).

The simulation of offshore wind is very interesting, and in this sense, Seixas et al. [254] design a new simulation model with interesting results.

Lave et al. [255] use the wavelet variability model to upscale irradiance measured in Puerto Rico to simulate photovoltaic power plants.

\subsubsection{Energy Storage}

Continuing with the energy storage, small-scale storage is also interesting, therefore, Pavkovic et al. [256] evaluate the results of condenser banks, flywheels and compressed air (as storage).

Storage can be hybridized with wind systems, in this sense Zhao et al. [257] dimensions an optimal system using adiabatic compressed air and flywheel, and employs a spectrum analysis method. 
But storage is also associated with photovoltaic systems, and in this sense, Gitizadeh and Fakharzadegan [258] optimize the capacity of the battery associated with a photovoltaic plant, and use mixed integer programming model.

Following the photovoltaic systems, Yoo et al. [259] employ a Kalman filter as hybrid battery management in a residential environment. The authors show that storage management is more efficient and reliable through advanced techniques. The results obtained demonstrate optimal storage management.

ANN have been used in multiple applications in SG, from the forecast of solar or wind resources (photovoltaic and wind) to electrical demand and management of electrical storage, as shown by Elsheikh et al. [260]. Barnes et al. [261] present a semi-Markov process model to model photovoltaic power and Brekken et al. [262] present sizing and control methodologies for a zinc-bromine flow battery-based energy based on ANN.

To summarize, Table 11 shows all the work described in this section. In the rows are shown different areas (tools for new plants and energy storage) while in the columns is shown the application rate on the creation of grid development models (AI and other techniques). As can be seen in the previous table, new models for the development of electricity grids are being implemented. These developments will be applied to improve the location of new generation plants and the deployment of storage. Again, the developments are based on $\mathrm{AI}$ and other simpler techniques.

Table 11. Summary of The Creation of Grid development Models.

\begin{tabular}{|c|c|c|}
\hline \multirow{2}{*}{$\begin{array}{l}\text { Summary of The Creation of } \\
\text { Grid Development Models }\end{array}$} & \multicolumn{2}{|c|}{$\begin{array}{c}\text { Grid Planning and Design: The Creation of Grid } \\
\text { Development Models }\end{array}$} \\
\hline & Artificial Intelligence & Other Techniques \\
\hline $\begin{array}{l}\text { Tools for Generating Plants and } \\
\text { Storage Energy }\end{array}$ & - & [252-255] \\
\hline Energy Storage & {$[260,262]$} & {$[256-259,261]$} \\
\hline
\end{tabular}

\subsection{Electrical Equipment}

The deployed devices must present greater demands, since there are numerous limitations of infrastructure expansion. Potential subareas will be explained. In many cases, detecting or replacing the affected device is complicated. In this sense, diagnostic tools are necessary. It is necessary to deploy devices that guarantee the absence of disturbances. Secondly, recharging points in the $S G$ are crucial. The intention is to study the impact of EV on SGs.

\subsubsection{Short-Circuit}

Dynamic short-circuit and dynamic voltage are very important, and in this sense, it is possible to use a control system for the restoration of the tension, as presented by Mahdianpoor et al. [263]. Boutsika and Papathanassiou [264] present the latest edition of the IEC 60909 standard, and the authors use this standard for the calculation of short circuit current in DG, for medium and low voltage grids. Three-phase short circuits can be addressed through ANN and pattern recognition, as discussed by Djukanovic et al. [265].

\subsubsection{Wave Quality}

The action of keeping the current sinusoid in phase with the voltage sinusoid is known as power compensation or power factor correction. For this, Kabir and Mahbub) [266] present a new device, the device includes active power filter (APF), dynamic voltage restorer (DVR) and unified power quality conditioner (UPQC). López-Martín et al. [267] propose a controller for the correction of the power factor, whose operation is based on the measurement of the harmonic voltage distortion. The device is based on a linear model. 


\subsubsection{EV}

Regarding EVs, Hua et al. [268] dimension optimal programming of EV recharge, and also, they reduce the imbalances produced and the voltage limits.

Nunes et al. [269] explore the possible complementarities between wind and solar power with EVs charging, the model used is EnergyPLAN. Zhu et al. [270] present an economic dispatch model (high-dimensional, non-linear, and stochastic problem and its solution require powerful methods) that considers EV charging, battery stations, and wind farms.

Wang et al. [271] propose a planning model for EV charging points, as well as optimal expansion strategies for the location of charging stations. The model is based on a mixed-integer linear programming model.

To summarize, Table 12 shows all the work described in this section. In the rows are shown different areas (short-circuit, quality and EV) while in the columns is shown the application rate on electrical equipment (AI and models with DG or storage). As can be seen in the previous table, it is necessary to deploy new electrical equipment, to tackle short circuit problems, wave quality and the incorporation of the EV. Again, the developments are based on AI and other simpler techniques, and in addition, models that integrate DG and storage will be necessary.

Table 12. Summary of Electrical Equipment.

\begin{tabular}{ccc}
\hline \multirow{2}{*}{$\begin{array}{c}\text { Summary of Electrical } \\
\text { Equipment }\end{array}$} & \multicolumn{2}{c}{ Grid Planning and Design: Electrical Equipment } \\
\cline { 2 - 3 } & Artificial Intelligence or Others & Models with DG or Storage \\
\hline Short-Circuit & {$[65,263]$} & {$[264]$} \\
\hline Wave Quality & {$[266]$} & {$[267]$} \\
\hline EV & {$[268,271]$} & {$[269,270]$} \\
\hline
\end{tabular}

\subsection{Development Alternatives of the Electrical Grid of the Future}

The transport and distribution grids should play new roles, and this section will tackle this issue. Potential subareas will be explained:

- The appearance of DG in points close to consumption, and improvements in control techniques, will lead to the development of this new SG.

- VPP or microgrid are a way to add the DG, and more and more these are being integrated into the SG. The figure of the aggregator will take a fundamental role in the appearance of the new SG.

- Advances must achieve new protection devices, which must be intelligent. The increase in generation and consumption will make the detection and clearing times of the faults shorten.

After the review of the works, the author has considered grouping them in the following subsections: Microgrids, Aggregating Distributed Generation and Storage and Protections.

\subsubsection{Microgrids}

Regarding microgrids, some authors propose programming of resources based on linear optimization problem with privacy constraints, such as Wang et al. [272].

Vaccaro et al. [273] employ self-organized agents for self-organization, and thus solve the problem of control and monitoring of a microgrid.

It is possible to obtain optimal management of resources with the microgrid in island mode, and $\mathrm{Xu}$ and Li [274] propose a distributed strategy, with a MAS framework, similar to Gómez-Sanz et al. [95].

The forecast is very important in microgrids, Sáez et al. [275] propose a fuzzy prediction interval models where the model uses solar and wind generation and local load from the microgrid. Hernández et al. [276] address the microgrid STLF problem through a two-stage model, in which the first stage estimates the peak and valley value of the next day, and in the second stage the full 
prediction of the next day is performed; also, Hernández et al. [277] present a new solution for STLF in microgrids, based on a three-stage architecture, the first stage makes pattern recognition by means of a SOM model, the second stage clusters the patterns by k-means and in the third stage the forecast is made (by cluster) using a perceptron model.

\subsubsection{Aggregating Distributed Generation and Storage}

Relating to aggregating distributed generation and storage, Ioakimidis et al. [278] understands the grid infrastructure as the space that includes renewable microgenerators, and the EV battery is seen as a local storage; the authors define the term energy box, and they use a multi-objective dynamic stochastic programming model as a solution to the problem.

It is possible to find a scenario with maximum income for the aggregator and lower costs for the recharge of the EV and consumers, as compiled by Amirioun and Kazemi [279].

Regarding VPP, Petersen et al. [280] model the flexible consumers as discrete batch processes, and authors develop tailored versions of the metaheuristic algorithms hill climber. Pandzic et al. (2913) [281] consider a weekly self-scheduling of a VPP and the optimal dispatch problem is formulated as a mixed-integer linear programming model. Bai et al. [282] apply nonlinear mixed-integer programming with inter-temporal constraints for the optimal dispatch strategy of a VPP, and they apply the fruit fly algorithm. According to Pandzic et al. [283], the VPP sells and purchases electricity in both the day-ahead and the balancing markets seeking to maximize its expected profit, the offering problem is cast as a two-stage stochastic mixed-integer linear programming model. Gong et al. [284] present an operation optimization model of VPP with a fuzzy multiple objective optimization problems. Mnatsakanyan and Kennedy [285] eliminate the dependence of price elasticity of demand in a VPP, and for them presents a new DR scheme focused on the final choice of load profiles, minimizing the cost of the system.

\subsubsection{Protections}

Relating to protections, Xyngi and Popov [286] propose a new protection system in scenarios with a high degree of renewable penetration, and they use an intelligent algorithm with direct interaction with field protections.

Garau et al. [287] propose the use of the public mobile telecommunication system 4G long term evolution (LTE), for the location and restoration of failures in the SG. The authors propose a simulation tool based on advanced AI techniques.

To summarize, Table 13 shows all the work described in this section. In the rows are shown different areas (microgrids, DER and protections) while in the columns is shown the application rate on development alternatives of the electrical grid of the future (AI and linear techniques). As can be seen in the previous table, new grid developments will be necessary, such as microgrids, DER with storage and new protections. To achieve this, advances are using AI and similar techniques, but also MAS.

Table 13. Summary of Development Alternatives of the Electrical Grid of the Future.

\begin{tabular}{ccc}
\hline $\begin{array}{c}\text { Summary of Development } \\
\text { Alternatives of the Electrical } \\
\text { Grid of the Future }\end{array}$ & \multicolumn{2}{c}{$\begin{array}{c}\text { Grid Planning and Design: Development Alternatives of the } \\
\text { Electrical Grid of the Future }\end{array}$} \\
\cline { 2 - 3 } Microgrids & $\begin{array}{c}\text { Artificial Intelligence or MAS } \\
\text { Linear Techniques and Similar }\end{array}$ & {$[272]$} \\
\hline $\begin{array}{c}\text { Aggregating Distributed } \\
\text { Generation and Storage }\end{array}$ & {$[95,273-277]$} & {$[279-281,285]$} \\
\hline Protections & {$[278,282-284]$} & - \\
\hline
\end{tabular}




\subsection{Alternative Development Strategies as regards the Grid of the Future}

The dramatic increase in demand will require the development and research of new strategies for the development of grid infrastructures. Potential subareas will be explained:

- A line designed for alternating current, but carrying direct current can evacuate more energy.

- A possible and optimal solution will be to increase the voltage levels in the lines. This requires an adaptation and development of the current equipment.

After the review of the works, the author has considered grouping them in the following subsections: Direct Current and Extra High Voltage.

\subsubsection{Direct Current}

Patrao et al. [288] discuss the importance of DC microgrids, but DC is also important in transport networks; the authors demonstrate the efficiency in the management through a DC microgrid versus the management in an $\mathrm{AC}$ microgrid; the non-existence of conversion stages makes the system more efficient. Wang et al. [289] present a genetic algorithm for optimal stationary energy storage systems locating and sizing in urban rail transit; these authors again demonstrate the efficiency in storage management through genetic algorithms.

Choi et al. [290] propose a voltage control in a DC microgrid, and this control is cooperative. The authors solve the problem of voltage control in a microgrid DC by means of a controller managed by a management algorithm of the DG and storage. The results shown are highly efficient.

Ko et al. [291] apply the Newton-Raphson method to solve nonlinear equations, which are applied to a programming algorithm of a DC storage system. The solution is validated in a DC environment, with electrical storage, a photovoltaic system and DC loads.

\subsubsection{Extra High Voltage}

According to high voltage or extra high voltage, Hwang et al. [292] apply cryogenics to the bushes of the lines, and validate two prototypes of 60 and $100 \mathrm{kV}$.

Qiao et al. [293] present a new finite-difference-based flux tracing method for analyzing the ionized field (non-linear algebraic equations are used).

New controllers are designed, specifically a new controller for HVDC converters, which has better results compared to non-linear feedback linearization control (Arioua et al. [294]).

To summarize, Table 14 shows all the work described in this section. In the rows are shown different areas (direct current and extra high voltage) while in the columns is shown the application rate on alternative development strategies as regards the grid of the future (AI and non-linear techniques and numeric methods). As can be seen in the previous table, new grid developments will be necessary, in this case, oriented to the deployment of an electrical grid in direct current and extra high voltage. To achieve this, the advances are using $\mathrm{AI}$ and similar techniques, but also other classical numerical techniques.

Table 14. Summary of Alternative Development Strategies as Regards the Grid of the Future.

\begin{tabular}{ccc}
\hline \multirow{2}{*}{$\begin{array}{c}\text { Summary of Alternative } \\
\text { Development Strategies as } \\
\text { Regards the Grid of the Future }\end{array}$} & \multicolumn{2}{c}{$\begin{array}{c}\text { Grid Planning and Design: Alternative Development Strategies as } \\
\text { Regards the Grid of the Future }\end{array}$} \\
\cline { 2 - 3 } & $\begin{array}{c}\text { Artificial Intelligence and } \\
\text { Non-Linear Techniques }\end{array}$ & $\begin{array}{c}\text { Linear Techniques and Numeric } \\
\text { Methods }\end{array}$ \\
\hline Direct Current & {$[289]$} & {$[290,291]$} \\
\hline Extra High Voltage & {$[293,294]$} & {$[292]$} \\
\hline
\end{tabular}




\section{Metering}

The new grid plays a double role (producer and consumer), therefore, new agents are necessary in this scenario, such as the creation of the prosumer (consumer and generator). This scenario with purchase and sale by customers requires a new regularized market, which must be managed by the operations center and will be decentralized. The communications between the SG and the clients will allow DR to be done, in addition to the operation of the SG itself. The demand management of the future network must be dynamic, and decision making will be in real time, optimizing the processes of generation and consumption. In addition, the consumer will receive orders in real time to vary their behavior. Therefore, the lines of investigation placed in the area of Metering are:

- Metering and Control Equipment and Technologies for the Grid-Customer Interface.

- DR.

\subsection{Metering and Control Equipment and Technologies for the Grid-Customer Interface}

The management system must be interoperable, so it is necessary to define, implement and validate a system with these characteristics. The real time will allow reacting to price stimuli, making the system more dynamic and more complicated to manage. Potential subareas will be explained:

- The measurement and control devices must take into account the large amount of information that they must process and transmit, and they will be teams with interaction with the client.

- These new devices must have an advanced communication with the operation center.

- The interaction between client and final device must be clearly defined.

After the review of the works, the author has considered grouping them in the following subsections: Managing Demand and DG with Metering, Communications Systems Between the Metering and Demand Management and Interaction Between the Metering and the Customer's Installation.

\subsubsection{Managing Demand and DG with Metering}

According to devices for managing demand and DG with metering, Bai et al. [295] address a complex solution for a bidirectional recharge of EV in a fully hierarchical SG; for this, the authors implement a nonlinear complementarity optimization model. A new framework for interaction between the SG and the clients, and in real time, is developed by Mondal et al [220], while the QoS is assured by a Bayesian Nash equilibrium.

\subsubsection{Communications Systems Between the Metering and Demand Management}

Relating to communications systems between the metering and demand management, as Yan et al. [296] show, SG must ensure a reliable and safe energy supply, in addition, SG must have self-healing mechanisms, all in a secure digital communications environment.

An interesting topic is to have cognitive radio networking for the multimedia application, and all of them through the infrastructure deployed in the SG, as addressed and studied by Wang et al. [297].

In this sense, formulations based on the non-cooperative game model and the Nash equilibrium like solution are interesting solutions to apply in the transmission of SG, as shown by Lin et al. [298].

Kallitsis et al. [299] introduce a framework for optimal resource allocation in SGs that also considers the uncertainty in message signaling; authors propose an iterative, decentralized algorithm for its solution, the algorithm requires only $\mathrm{O}(\mathrm{N})$ messages per network user per iteration, where $\mathrm{N}$ is the number of users.

One solution for the neighborhood area network is to apply wireless technologies. Ye et al. [300] propose a sustainable, economic and very flexible solution; for this, the authors develop an optimization algorithm to minimize the total cost, the algorithm is based on AI. 
One way to customize several services is using network virtualization (NV), Lv et al. [301] propose an NV-based framework for SG communications, and the heuristic solution is developed to solve the problem effectively and efficiently.

\subsubsection{Interaction Between the Metering and the Customer's Installation}

Rhodes et al. [302] present the results of a study where they show a negative correlation between the use of energy and the knowledge of it. Instead, they show a positive correlation between energy with discounts and the use of it.

Olmos et al. [303] establish a theoretical framework to quantify the results of DR. Based on certain DR actions, the authors are able to determine certain demand behaviors.

The energy interface must be bidirectional, acting as a service provider and consumer thereof, as presented by Lee et al. [304]. At the same time, this interface must protect the energy resources.

To summarize, Table 15 shows all the work described in this section. In the rows are shown different areas (managing demand and DG, communication between demand and metering and interaction between the metering and the customer's installation) while in the columns is shown the application rate on metering and control equipment and technologies for the grid-customer interface (AI and other methods). As can be seen in the previous table, the measure is key for many applications in the SG. For example, the measure is critical for interacting with customers, as well as for managing DG and storage. To achieve this, the advances are using AI and similar techniques, but also other classical numerical techniques.

Table 15. Summary of Metering and Control Equipment and Technologies for the Grid-Customer Interface.

\begin{tabular}{lcc}
\hline \multirow{2}{*}{$\begin{array}{c}\text { Summary of Metering and } \\
\text { Control Equipment and } \\
\text { Technologies for the }\end{array}$} & \multicolumn{2}{c}{$\begin{array}{c}\text { Metering: Metering and Control Equipment and Technologies for the } \\
\text { Grid-Customer Interface }\end{array}$} \\
\cline { 2 - 4 } \begin{tabular}{c} 
Grid-Customer Interface \\
\cline { 2 - 3 }
\end{tabular} & $\begin{array}{c}\text { Artificial Intelligence and } \\
\text { Non-Linear Techniques }\end{array}$ & $\begin{array}{c}\text { Linear Techniques and Other } \\
\text { Methods }\end{array}$ \\
\hline $\begin{array}{c}\text { Managing Demand and DG with } \\
\text { Metering }\end{array}$ & {$[295]$} & {$[220]$} \\
\hline $\begin{array}{c}\text { Communications Systems } \\
\text { Between the Metering and } \\
\text { Demand Management }\end{array}$ & {$[301]$} & {$[297-300]$} \\
\hline $\begin{array}{c}\text { Interaction Between the } \\
\text { Metering and the Customer's } \\
\text { Installation }\end{array}$ & - & {$[302,303]$} \\
\hline
\end{tabular}

\subsection{Demand Response}

The interaction between supply and demand is achieved through an active $D R$. In this way, it is possible to alleviate the cost of energy. Potential subareas will be explained:

- It is necessary to be able to change the behavior of consumers, and for this, it is necessary to know the sectoral demand.

- Social awareness programs are essential, in order to explain the relationship between $D R$ and energy prices.

- DR must be associated with a good policy for the use of energy storage. Storage will provide the flexibility that DR requires.

After the review of the works, the author has considered grouping them in the following subsections: Flexibility of Electricity Demand by Sector/Usage, Demand Management Programs and Energy Storage Applications in Response to Demand. 


\subsubsection{Flexibility of Electricity Demand by Sector/Usage}

According to flexibility of electricity demand, Christakou et al. [305] propose a decentralization of DR, called grid-explicit congestion notification (GECN) based on a linear algorithm.

Khojasteh and Jadid [306] present a system of DR at two levels, where the property belongs to retailers, the information gap decision theory (IGDT - a non-probabilistic decision theory) approach is addressed.

Oh and Hildreth [228] work on the possibility of accepting energy supply cuts, and for them they present a model based on activity-based costing and stochastic programming.

A distributed management system model takes advantage of the bidirectional infrastructure, and this system is used by Mohsenian-Rad et al. [307]. The solution is based on game theory and formulates an energy consumption scheduling game.

As Hirst [308] shows, it is possible to use a multi-step system to evaluate the demand program, namely: identify existing markets, calculate technical potential and profitable.

\subsubsection{Demand Management Programs}

Relating to demand management programs, Safdarian et al. [309] incorporate DR in DisCos' short-term decision model in a real-time pricing environment wherein consumers are charged based on hourly varying prices and the model is a mixed integer linear programming problem.

Sovacool [310] addresses demand management with a mixed integer non-linear programming problem. Ghazvini et al. [311] address the problem of losses in different markets. The authors propose a two-stage stochastic programming problem, which has two stages to establish the best DR programs. Gudi et al. [312] take advantage of the technique of change of load to formulate a management strategy on the demand side (a heuristic-based on EA) of the future.

\subsubsection{Energy Storage Applications in Response to Demand}

According to energy storage applications in response to demand, Wang et al. (2014) [313] present a DR and battery storage coordination algorithm for providing microgrid tie-line smoothing services.

As Erdinc et al. [314] show, the sizing of additional DG and energy storage systems to be applied in smart households is very important; authors use a mixed-integer linear programming.

Faria et al. [315] employ a methodology that includes DG and DR, for a scenario with a distribution grid operated by a virtual power player with mixed-integer non-linear programming.

Home energy management is approached in a coordinated manner and it is solved as a multi-stage stochastic optimization problem by Chang et al. [316].

To summarize, Table 16 shows all the work described in this section. In the rows are shown different areas (flexibility of demand, demand management programs and energy storage applications) while in the columns is shown the application rate on demand response (AI and other methods). As can be seen in the previous table, it is necessary to develop new programs that enable the application of DR. DR must be integrated with storage and DR must guarantee flexibility to the system. To achieve this, the advances are using AI and similar techniques, but also other classical numerical techniques.

Table 16. Summary of Demand Response.

\begin{tabular}{ccc}
\hline \multirow{2}{*}{\begin{tabular}{c} 
Summary of Demand Response \\
\cline { 2 - 3 }
\end{tabular}} & $\begin{array}{c}\text { Metering: Demand Response } \\
\text { Artificial Intelligence and } \\
\text { Non-Linear Techniques }\end{array}$ & $\begin{array}{c}\text { Linear Techniques and Other } \\
\text { Methods }\end{array}$ \\
\hline $\begin{array}{c}\text { Flexibility of Electricity Demand } \\
\text { by Sector/Usage }\end{array}$ & {$[306,307]$} & {$[228,305]$} \\
\hline $\begin{array}{c}\text { Demand Management Programs } \\
\begin{array}{c}\text { Energy Storage Applications in } \\
\text { Response to Demand }\end{array}\end{array}$ & {$[310,312]$} & {$[309,311]$} \\
\hline
\end{tabular}




\section{Conclusions}

The paper has presented the principal applications concerning the SGs. The use of AI-based techniques is being used extensively in SG. For example, this work has analyzed around 316 works, of which at least 115 works are based on AI. This represents 37\% of the works shown, being the majority of the last decade. It has already been commented that the SG focuses on ICT, and this is demonstrated by the analysis of a large number of works focused on IA. Statistical models, linear techniques, not-linear techniques, expert systems, ANN, AI and other methods have been used in the four areas of the SGs. The area with the highest number of papers presented is "Operation and Control", and within this "Enterprise Architecture". The second area with the largest number of jobs in AI is "Grid Planning and Design", and within this "Development Alternatives of the Electrical Grid of the Future". The third area with the largest number of jobs in AI is "Maintenance and Lifespan Management", and within this "Advanced Decision-Making Systems". In last position is "Metering", and within this, the subarea with the most jobs in AI is "Demand Response".

Therefore, it can be said that the AI-based techniques are of majority use in the SG, regardless of their area of interest. Initially, the AI was used for forecasting models (demand and later generation), but nowadays Ai is used for the whole compendium of services associated with the SG.

It is very likely that the distribution infrastructure (and its control) does not look anything like the present when twenty years pass. This will be due to the incorporation of advanced measurement, DG and distributed storage. This will allow self-healing, QoS, cybersecurity, operate reliably and economically, etc.

Operation and control, maintenance and lifespan management, grid planning and design and metering need the applications of science. The evolution of the SGs will need new developments and major efficiency. The SG needs algorithms, materials, devices and other new paradigms for its future development.

The operation and precise control of new intelligent equipment, together with the architecture of communications and new protocols, allows the networks to be smarter. With this advance, the electric companies will be able to guarantee a better supply and QoS, and increase their penetration percentage of renewables in the network. The new applications should be integrated into current systems, and if possible, easily. Operation and control involve making the current network as anactive and future electrical grid. To achieve this, it is necessary to develop advanced equipment, with new communication systems that allow complete automation (transport, distribution and low voltage). New fault detection techniques are also needed to enable the integration of distributed resources. The new support tools for the operation should be integrated into the architecture of the company, becoming a new company that integrates new services.

Maintenance and lifespan management require new smart signals from new equipment. In addition, the new applications of the SG will allow asset management and decision-making systems. The operation and maintenance have become a crucial task in many aspects of the SG, for example, these are essential in large renewable generation plants (mainly wind and photovoltaic systems), but also for the management and management of the transport network and distribution.

The evolution of the current electricity network will allow the design and implementation of new networks of the future. These new networks will bring new development models and new functionalities. New paradigms such as microgrids will allow renewable generation sources to be integrated in a massive way, but for this, it is necessary to plan and design electrical grids in another way. Therefore, everything must evolve consistently, from the grid itself to the equipment that composes it.

Perhaps the fundamental pillar of the SG is the metering. New equipment is being developed, which will allow smart metering, supported by the appropriate communications architecture. This advanced metering will allow the interaction with the final clients, who will be able to take part in the decisions of the SG. The measure of future will allow the integration of the great forgotten in the electrical grids, the low tension; new developments of low voltage protocols will allow the supervision 
and control of it, and why not, the integration of renewable generation sources and their management through Smart Metering.

The SG is presented as an integrator of new equipment, new tools, new protocols, new systems, new paradigms, greater integration of renewables, etc. All of the above will make the current networks become the future SGs, and the term Smart can be decisive and fundamental in them.

This document demonstrates the need for the evolution of the current electrical infrastructure. This need is due to the constant evolution of the electrical system. This evolution implies the appearance of new actors on the stage, namely: DG, DR, microgrid, EV, etc. The above will make it a necessary improvement in the industry related to the electrical infrastructure, now called SG. The appearance of new devices in the infrastructure should be supported by the development of new planning, management and simulation tools. Both the new hardware and the software will be supported by the latest trends in design and development models, specifically models based on advanced techniques (AI and similar); however, some authors continue using models based on classical systems (linear, differential, etc.). But everything has its advantages and disadvantages, AI-based techniques allow to find a quick solution to problems, but on the contrary you lose control over it; on the other hand, techniques based on linear techniques make it difficult to find the solution quickly (they need to know the problem very well), but on the contrary, they make the user perfectly understand the problem to be solved.

The current electrical infrastructure is evolving, since it incorporates new elements such as DG, $\mathrm{DR}$, microgrids, etc.; this fact will require the current infrastructure to evolve and become a more flexible infrastructure. The traditional electrical and electronic devices will require a more novel and ambitious development. In this sense, it is possible that the current industry shows some reluctance to achieve this, but step by step, the electrical industry will accept and demand these changes.

Funding: This research received no external funding.

Conflicts of Interest: The authors declare no conflict of interest.

\section{List of Acronyms}

$\begin{array}{ll}\text { cGA } & \text { compact Genetic Algorithm } \\ \text { AAM } & \text { Advanced Asset Management } \\ \text { ABDP } & \text { Accumulated Bandwidth Distance Product } \\ \text { ADO } & \text { Advanced Distribution Operations } \\ \text { AHP } & \text { Analytic Hierarchy Process } \\ \text { AI } & \text { Artificial Intelligence } \\ \text { AMI } & \text { Advanced Metering Infrastructure } \\ \text { ANN } & \text { Artificial Neural Network } \\ \text { APF } & \text { Active Power Filter } \\ \text { ARIMA } & \text { AutoRegressive Integrated Moving Average } \\ \text { ATO } & \text { Advanced Transmission Operations } \\ \text { C\&I } & \text { Commercial and Industrial } \\ \text { CE } & \text { Control Entity } \\ \text { CMD } & \text { Condition Monitoring and Diagnosis } \\ \text { CPS } & \text { Cyber-Physical Systems } \\ \text { DER } & \text { Distributed Energy Resource } \\ \text { DFA } & \text { Distribution Fault Anticipation } \\ \text { DG } & \text { Distributed Generation } \\ \text { DGAD } & \text { Distributed General-Anomaly Detection } \\ \text { DNP3 } & \text { Distributed Network Protocol 3.0 }\end{array}$




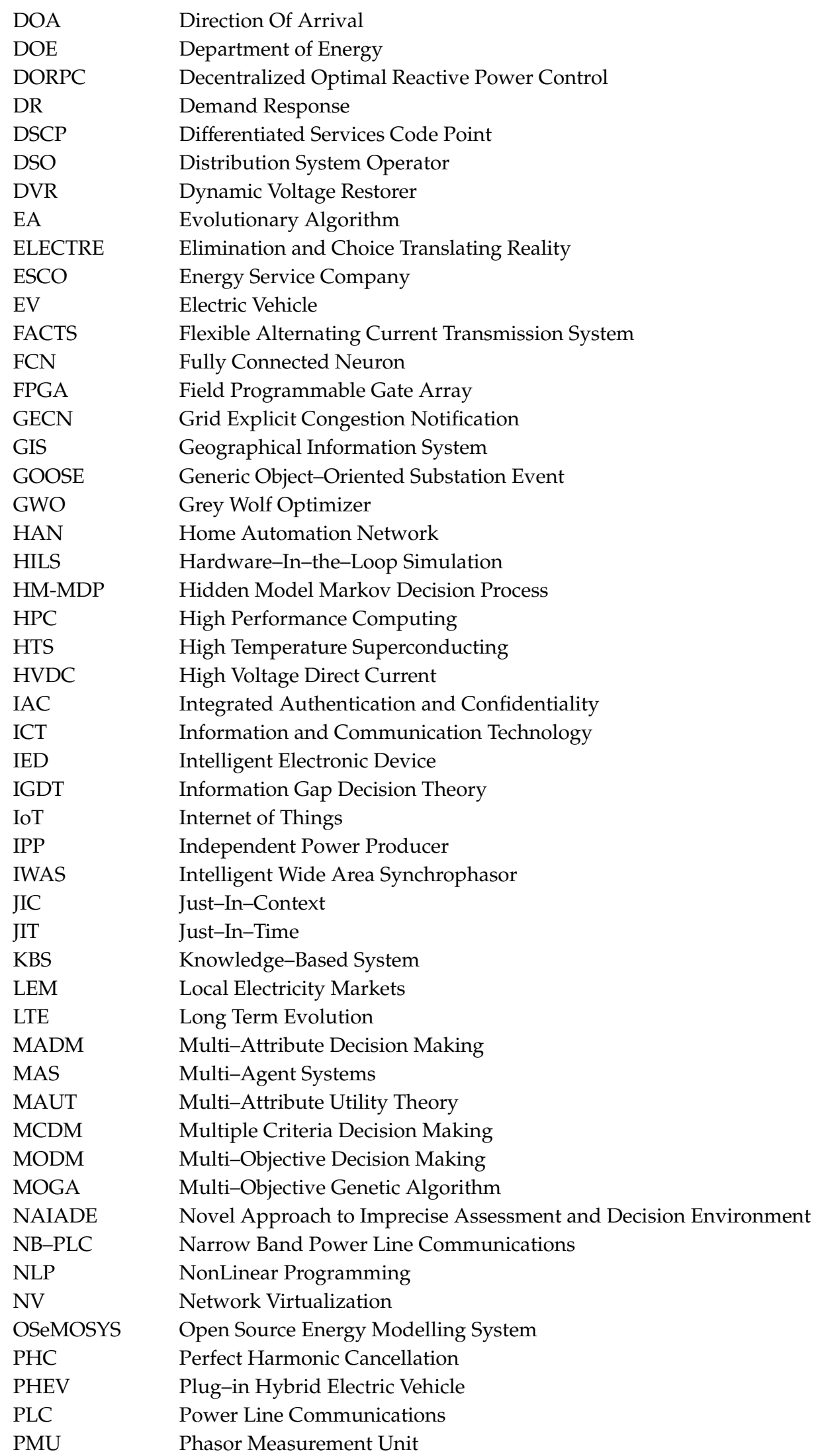




$\begin{array}{ll}\text { PPA } & \text { PMU Performance Analyzer } \\ \text { PROMETHEE } & \text { Preference Ranking Organization Method for Enrichment Evaluation } \\ \text { QOS } & \text { Quality of Service } \\ \text { RPL } & \text { Routing Protocol for LLN } \\ \text { SAW } & \text { Simple Additive Weighting } \\ \text { SCADA } & \text { Supervisory Control and Data Acquisition } \\ \text { SCSN } & \text { Spectrum-aware and Cognitive Sensor Network } \\ \text { SEDMS } & \text { Smart Energy Distribution and Management System } \\ \text { SES } & \text { Socio-Ecological System } \\ \text { SG } & \text { Smart Grid } \\ \text { SGHSA } & \text { Self-adaptive Global-based Harmony Search Algorithm } \\ \text { SM } & \text { Smart Meter } \\ \text { SMAA } & \text { Stochastic Multi-Objective Acceptability Analysis } \\ \text { SMILP } & \text { Sequential Mixed Integer Linear Programming } \\ \text { SoC } & \text { State of Charge } \\ \text { SOA } & \text { Service-Oriented Architecture } \\ \text { SOM } & \text { Self-Organization Map } \\ \text { STLF } & \text { Short-term Load Forecasting } \\ \text { SVM } & \text { Support Vector Machine } \\ \text { UPQC } & \text { Unified Power Quality Conditioner } \\ \text { UPS } & \text { Uninterruptible Power Supply } \\ \text { VPP } & \text { Virtual Power Plant } \\ \text { VVO } & \text { voltage VAR optimization } \\ \text { WAMS } & \text { Wide Area Monitoring Systems } \\ \text { WAN } & \text { Wide Area Net } \\ & \end{array}$

\section{References}

1. European Technology Platform SmartGrids. Available online: http://www.smartgrids.eu/ (accessed on 1 April 2015).

2. U.S. Department of Energy (DOE). Available online: http://energy.gov/ (accessed on 1 May 2015).

3. StarGrid EU. European Distributed Energy Resources Laboratories. Activity Report 2014/2015; European Distributed Energy Resources Laboratories (DERlab) e.V.: Kassel, Germany, 2015.

4. Vu, K.; Raleigh, N.C.; Novosel, D. Grids get smart protection and control. IEEE Comput. Appl. Power 1997, 10, 40-44. [CrossRef]

5. O'Driscoll, E.; O'Donnell, G.E. Industrial power and energy metering-A state-of-the-art review. J. Clean. Prod. 2013, 41, 53-64. [CrossRef]

6. Ruiz-Romero, S.; Colmenar-Santos, A.; Mur-Pérez, F.; López-Rey, A. Integration of distributed generation in the power distribution network: The need for smart grid control systems, communication and equipment for a smart city-Use cases. Renew. Sustain. Energy Rev. 2014, 38, 223-234. [CrossRef]

7. Arai, J.; Iba, K.; Funabashi, T.; Nakanishi, Y.; Koyanagi, K.; Yokoyama, R. Power electronics and its applications to renewable energy in Japan. IEEE Circuits Syst. Mag. 2008, 8, 52-66. [CrossRef]

8. Kezunovic, M. Translational Knowledge: From Collecting Data to Making Decisions in a Smart Grid. Proc. IEEE 2011, 99, 977-997. [CrossRef]

9. Dervos, C.T.; Paraskevas, C.D.; Skafidas, P.D.; Vassiliou, P. A Complex Permittivity Based Sensor for the Electrical Characterization of High-Voltage Transformer Oils. Sensors 2005, 5, 302-316. [CrossRef]

10. Di Fazioa, A.R.; Fuscoa, G.; Russoa, M.; Valeria, S.; Noceb, C.; Amuraca, G. A smart device for islanding detection in distribution system operation. Electr. Power Syst. Res. 2015, 120, 87-95. [CrossRef]

11. Zhou, N.-C.; Lou, X.-X.; Yu, D.; Wang, Q.-G.; Wang, J.-J. Harmonic Injection-Based Power Fluctuation Control of Three-Phase PV Systems under Unbalanced Grid Voltage Conditions. Energies 2015, 8, 1390-1405. [CrossRef]

12. Milanés-Montero, M.I.; Gallardo-Lozano, J.; Romero-Cadaval, E.; González-Romera, E. Hall-Effect Based Semi-Fast AC On-Board Charging Equipment for Electric Vehicles. Sensors 2011, 11, 9313-9326. [CrossRef] [PubMed] 
13. Zhao, B.; Song, Q.; Liu, W.; Xiao, Y. Next-Generation Multi-Functional Modular Intelligent UPS System for Smart Grid. IEEE Trans. Ind. Electron. 2013, 60, 3602-3618. [CrossRef]

14. Yang, M.-T.; Gu, J.-C. Optimal Coordination of Automatic Line Switches for Distribution Systems. Energies 2012, 5, 1150-1174. [CrossRef]

15. Yun, S.-Y.; Hwang, P.-I.; Moon, S.-I.; Kwon, S.-C.; Song, I.-K.; Choi, J.-H. Development and Field Test of Voltage VAR Optimization in the Korean Smart Distribution Management System. Energies 2014, 7, $643-669$. [CrossRef]

16. Wang, Z.; Wang, J.; Chen, B.; Brgovic, M.M.; He, Y. MPC-Based Voltage/Var Optimization dor Distribution Circuits With Distributed Generators and Exponential Load Models. IEEE Trans. Smart Grid 2014, 5, 2412-2420. [CrossRef]

17. Majumdar, A.; Agalgaonkar, Y.P.; Pal, B.C.; Gottschalg, R. Centralized Volt-Var Optimization Strategy Considering Malicious Attack on Distributed Energy Resources Control. IEEE Trans. Sustain. Energy 2018, 9, 148-156. [CrossRef]

18. Zhao, B.; Li, H.; Wang, M.; Che, Y.; Liu, S.; Yang, D.; Yang, C.; Hu, Y.; Chen, Z. An Optimal Reactive Power Control Strategy for a DFIG-Based Wind Farm to Damp the Sub-Synchronous Oscillation of a Power System. Energies 2014, 7, 3086-3103. [CrossRef]

19. Zeineldin, H.H.; El-Saadany, E.F.; Salama, M.M.; Kasem Alaboudy, A.H.; Woon, W.L. Optimal Sizing of Thyristor-Controlled Impedance for Smart Grids With Multiple Configurations. IEEE Trans. Smart Grid 2011, 2, 528-537. [CrossRef]

20. Li, J.; He, Z.; Wang, Y.; Lv, J.; Zhao, L. A Two-Dimensional Cloud Model for Condition Assessment of HVDC Converter Transformers. Energies 2012, 5, 157-167. [CrossRef]

21. Wang, J.; Yang, Q.; Sima, W.; Yuan, T.; Zahn, M. A Smart Online Over-Voltage Monitoring and Identification System. Energies 2011, 4, 599-615. [CrossRef]

22. Jiang, X.; Xia, Y.; Hu, J.; Zhang, Z.; Shu, L.; Sun, C. An S-Transform and Support Vector Machine (SVM)-Based Online Method for Diagnosing Broken Strands in Transmission Lines. Energies 2011, 4, 1278-1300. [CrossRef]

23. Pasdar, A.; Mehne, H.H. Intelligent three-phase current balancing technique for single-phase load based on smart metering. Electr. Power Energy Syst. 2011, 33, 693-698. [CrossRef]

24. Ananthavijayan, R.; Shanmugam, P.K.; Padmanaban, S.; Hol-Nielsen, J.B.; Blaabjerg, F.; Fedak, V. Software Architectures for Smart Grid System-A Bibliographical Survey. Energies 2019, 12, 1183. [CrossRef]

25. Mohassel, R.R.; Fung, A.; Mohammadi, F.; Raahemifar, K. A survey on Advanced Metering Infrastructure. Electr. Power Energy Syst. 2014, 63, 473-484. [CrossRef]

26. Bhatt, J.; Shah, V.; Jani, O. An instrumentation engineer's review on smart grid: Critical applications and parameters. Renew. Sustain. Energy Rev. 2014, 40, 1217-1239. [CrossRef]

27. Reinhardt, A.; Englert, F.; Christin, D. Averting the privacy risks of smart metering by local data preprocessing. Pervasive Mobile Comput. 2015, 16, 171-183. [CrossRef]

28. Diamantoulakisa, P.D.; Kapinasa, V.M.; Karagiannidisa, G.K. Big Data Analytics for Dynamic Energy Management in Smart Grids. Big Data Res. 2015, 2, 94-101. [CrossRef]

29. Niyato, D.; Wang, P. Cooperative Transmission for Meter Data Collection in Smart Grid. IEEE Commun. Mag. 2012, 50, 90-97. [CrossRef]

30. Wen, L.; Zhou, K.; Yang, S.; Li, L. Compression of smart meter big data: A survey. Renew. Sustain. Energy Rev. 2018, 91, 59-69. [CrossRef]

31. Zhang, J.; Hasandka, A.; Wei, J.; Shafiul Alam, S.M.; Elgindy, T.; Florita, A.R.; Hodge, B.M. Hybrid Communications Architectures for Distributed Smart Grid Applications. Energies 2018, 11, 871. [CrossRef]

32. Ahmed, M.; Alam, G.R.; Kamal, R.; Hong, C.S.; Lee, S. Smart Grid Cooperative Communication with Smart Relay. J. Commun. Netw. 2012, 14, 640-652. [CrossRef]

33. Li, P.; Guo, S.; Chen, Z. Joint Optimization of Electricity and Communication Cost for Meter Data Collection in Smart Grid. IEEE Trans. Emerg. Top. Comput. 2013, 1, 297-306. [CrossRef]

34. Huang, J.; Wang, H.; Qian, Y.; Wang, C. Priority-Based Traffic Scheduling and Utility Optimization for Cognitive Radio Communication Infrastructure-Based Smart Grid. IEEE Trans. Smart Grid 2013, 4, 78-86. [CrossRef]

35. Allalouf, M.; Gershinky, G.; Lewin-Eytan, L.; Naor, J. Smart Grid Network Optimization: Data-Quality-Aware Volume Reduction. IEEE Syst. J. 2014, 8, 450-460. [CrossRef] 
36. Markovic, D.S.; Zivkovic, D.; Branovic, I.; Popovic, R.; Cvetkovic, D. Smart power grid and cloud computing. Renew. Sustain. Energy Rev. 2013, 24, 566-577. [CrossRef]

37. Grosmangin, F. Diagnosis of the Location of Defects Accessible from MV Network Control System (SCADA). In Proceedings of the 14th International Conference and Exhibition on Electricity Distribution. Part 1. Contributions (IEE Conf. Publ. No. 438), Birmingham, UK, 2-5 June 1997; pp. 1-3.

38. Fan, Z.; Kulkarni, P.; Gormus, S.; Efthymiou, C.; Kalogridis, G.; Sooriyabandara, M.; Zhu, Z.; Lambotharan, S.; Chin, W.H. Smart Grid Communications: Overview of Research Challenges, Solutions, and Standardization Activities. IEEE Commun. Surv. Tutor. 2013, 15, 21-38. [CrossRef]

39. Erlinghagen, S.; Lichtensteiger, B.; Markard, J. Smart meter communication standards in EuropeA comparison. Renew. Sustain. Energy Rev. 2015, 43, 1249-1262. [CrossRef]

40. Albano, M.; Ferreira, L.L.; Pinho, L.M. Convergence of Smart Grid ICT Architectures for the Last Mile. IEEE Trans. Ind. Inform. 2015, 11, 187-197. [CrossRef]

41. Cataliotti, A.; Cipriani, G.; Cosentino, V.; Di Cara, D.; Di Dio, V.; Guaiana, S.; Panzavecchia, N.; Tinè, G. A Prototypal Architecture of a IEEE 21451 Network for Smart Grid Applications Based on Power Line Communications. IEEE Sens. J. 2015, 15, 2460-2467. [CrossRef]

42. Papadopoulos, T.A.; Kaloudas, C.G.; Chrysochos, A.I.; Papagiannis, G.K. Application of Narrowband Power-Line Communication in Medium-Voltage. IEEE Trans. Power Deliv. 2013, 28, 981-988. [CrossRef]

43. Yan, Y.; Hu, R.Q.; Das, S.K.; Sharif, H.; Quian, Y. An Efficient Security Protocol for Advanced Metering Infrastructure in Smart Grid. IEEE Netw. 2013, 27, 64-71. [CrossRef]

44. Yigit, M.; Gungor, V.C.; Tuna, G.; Rangoussi, M.; Fadel, E. Power line communication technologies for Smart grid applications: A review of advances and challenges. Comput. Netw. 2014, 70, 366-383. [CrossRef]

45. Kulkarni, P.; Gormus, S.; Zhong, F.; Motz, B. A mesh-radio-based solution for smart metering networks. IEEE Commun. Mag. 2012, 50, 86-95. [CrossRef]

46. Lu, X.; Wang, W.; Ma, J. An Empirical Study of Communication Infrastructures Towards the Smart Grid: Design, Implementation, and Evaluation. IEEE Trans. Smart Grid 2013, 4, 170-183. [CrossRef]

47. Li, Q.; Cao, G. Multicast Authentication in the Smart Grid With One-Time Signature. IEEE Trans. Smart Grid 2011, 2, 686-696. [CrossRef]

48. Zhou, J.; Hu, Q.; Quian, Y. Scalable Distributed Communication Architectures to Support Advanced Metering Infrastructure in Smart Grid. IEEE Trans. Parallel Distrib. Syst. 2012, 23, 1632-1642. [CrossRef]

49. Selga, J.M.; Zaballos, A.; Navarro, J. Solutions to the Computer Networking Challenges of the Distribution Smart Grid. IEEE Commun. Lett. 2013, 17, 588-591. [CrossRef]

50. Bicen, A.O.; Akan, O.B.; Gungor, V.C. Spectrum-aware and cognitive sensor networks for Smart grid applications. IEEE Commun. Mag. 2012, 50, 158-165. [CrossRef]

51. Abdullah, A.S.; Burt, G.M. An Advanced Protection Scheme for Enabling an LVDC Last Mile Distribution Network. IEEE Trans. Smart Grid 2014, 5, 2602-2609.

52. Wang, K.; Qiu, X.; Guo, S.; Qi, F. Fault Tolerance Oriented Sensors Relay Monitoring Mechanism for Overhead Transmission Line in Smart Grid. IEEE Sens. J. 2015, 15, 1982-1991. [CrossRef]

53. Salvadori, F.; Gehrke, C.S.; de Oliveira, A.C.; de Campos, M.; Sausen, P.S. Smart Grid Infrastructure Using a Hybrid Network Architecture. IEEE Trans. Smart Grid 2013, 4, 1630-1639. [CrossRef]

54. Bulucea, C.A.; Rosen, M.A.; Nicola, D.A.; Mastorakis, N.E.; Bulucea, C.A. Approaching the Processes in the Generator Circuit Breaker at Disconnection through Sustainability Concepts. Sustainability 2013, 5, 1161-1176. [CrossRef]

55. Mansson, M.; Johansson, B.; Nilsson, L.J. Assessing energy security: An overview of commonly used methodologies. Energy 2014, 73, 1-14. [CrossRef]

56. Sanchez-Sutil, F.; Hernández, J.C.; Tobajas, C. Overview of electrical protection requirements for integration of a smart DC node with bidirectional electric vehicle charging stations into existing AC and DC railway grids. Electr. Power Syst. Res. 2015, 122, 104-118. [CrossRef]

57. Ntalampiras, S. Fault Diagnosis for Smart Grids in Pragmatic Conditions. IEEE Trans. Smart Grid 2018, 9 , 1964-1971. [CrossRef]

58. Yang, Q.; Wang, R.; Sima, W.; Jiang, C.; Lan, X.; Zahn, M. Electrical Circuit Flashover Model of Polluted Insulators under AC Voltage Based on the Arc Root Voltage Gradient Criterion. Energies 2012, 5, 752-769. [CrossRef] 
59. Haiyang, Z.; Shande, L. Design of adaptive line protection under smart grid. In Proceedings of the 2011 International Conference on Advanced Power System Automation and Protection (APAP), Beijing, China, 16-20 October 2011; Volume 1, pp. 599-603.

60. Spitsa, V.; Ran, X.; Salcedo, R.; Martinez, J.F.; Ebrahem, R.; de León, F.; Czarkowski, D.; Zabar, Z. On the Transient Behavior of Large-Scale Distribution Networks During Automatic Feeder Reconfiguration. IEEE Trans. Smart Grid 2012, 3, 887-896. [CrossRef]

61. Yan, Y.; Li, J.; Gao, D.W. Condition Parameter Modeling for Anomaly Detection in Wind Turbines. Energies 2014, 7, 3104-3120. [CrossRef]

62. Deshpande, J.G.; Kim, E.; Thottan, M. Differentiated Services QoS in Smart Grid Communication Networks. Bell Labs Tech. J. 2011, 16, 61-82. [CrossRef]

63. Yang, X.; Zhang, X.-P.; Zhou, S. Coordinated algorithms for distributed state estimation with synchronized phasor measurements. Appl. Energy 2012, 96, 253-260. [CrossRef]

64. Aminifar, F.; Shahidehpour, M.; Fotuhi-Firuzabad, M.; Kamalinia, S. Power System Dynamic State Estimation with Synchronized Phasor Measurements. IEEE Trans. Instrum. Meas. 2014, 63, 352-363. [CrossRef]

65. Barchi, G.; Macii, D.; Petri, D. Synchrophasor Estimators Accuracy: A Comparative Analysis. IEEE Trans. Instrum. Meas. 2013, 62, 963-973. [CrossRef]

66. Barchi, G.; Fontanelli, D.; Macii, D.; Petri, D. On the Accuracy of Phasor Angle Measurements in Power Networks. IEEE Trans. Instrum. Meas. 2015, 64, 1129-1139. [CrossRef]

67. Kekatos, V.; Giannakis, G.B.; Wollenberg, B. Optimal Placement of Phasor Measurement Units via Convex Relaxation. IEEE Trans. Power Syst. 2012, 27, 1521-1530. [CrossRef]

68. Gopakumar, P.; Bharata, M.J.; Mohanta, D.K. Adaptative fault identification and classification methodology for smart power grids using synchronous phasor angle measurements. IET Gener. Transm. Distrib. 2015, 9, 133-145. [CrossRef]

69. Ma, J.; Zhang, P.; Fu, H.-J.; Bo, B.; Dong, Z.-Y. Application of Phasor Measurement Unit on Locating Disturbance Source for Low-Frequency Oscillation. IEEE Trans. Smart Grid 2010, 1, 340-346. [CrossRef]

70. Coury, D.V.; Silva, R.P.M.; Delbem, A.C.B.; Casseb, M.V.G. Programmable logic design of a compact Genetic Algorithm for phasor estimation real-time. Electr. Power Syst. Res. 2014, 107, 109-118. [CrossRef]

71. Kim, J.; Lee, B.; Han, S.; Shin, J.-H.; Kim, T.; Kim, S.; Moon, Y. Study of the Effectiveness of a Korean Smart Transmission Grid Based on Synchro-Phasor Data of K-WAMS. IEEE Trans. Smart Grid 2013, 4, 411-418. [CrossRef]

72. Hashiesh, F.; Mostafa, H.E.; Khatib, A.R.; Helal, I.; Mansour, M.M. An Intelligent Wide Area Synchrophasor Based System for Predicting and Mitigating Transient Instabilities. IEEE Trans. Smart Grid 2012, 3, 645-652. [CrossRef]

73. Ghosh, D.; Ghose, T.; Mohanta, D.K. Communication Feasibility Analysis for Smart Grid With Phasor Measurement Units. IEEE Trans. Ind. Inform. 2013, 9, 1486-1496. [CrossRef]

74. Robson, S.; Tan, G.; Haddab, A. Low-Cost Monitoring of Synchrophasors Using Frequency Modulation. Energies 2019, 12, 611. [CrossRef]

75. Stuart, E.; Larsen, P.H.; Goldman, C.A.; Gilligan, D. A method to estimate the size and remaining market potential of the U.S. ESCO (energy service company) industry. Energy 2014, 77, 362-371. [CrossRef]

76. Hannon, M.J.; Foxon, T.F.; Gale, W.F. The co-evolutionary relationship between Energy Service Companies and the UK energy system: Implications for a low-carbon transition. Energy Policy 2013, 61, 1031-1345. [CrossRef]

77. Plastow, J.W. Energy services for an electricity industry based on renewable energy. Power Eng. J. 2001, 15, 239-247. [CrossRef]

78. Ravindra, K.; Iyer, P.P. Decentralized demand-supply matching community microgrids and consumer demand response: A scenario analysis. Energy 2014, 76, 32-41. [CrossRef]

79. Driesen, J.; Katiraei, F. Design for Distributed Energy Resources. IEEE Power Energy Mag. 2008, 6, 30-40.

80. Poudineh, R.; Jamasb, T. Distributed generation, storage, demand response and energy efficiency as alternatives to grid capacity enhancement. Energy Policy 2014, 67, 222-231. [CrossRef]

81. Labanca, N.; Suerkemper, F.; Bertoldi, P.; Irrek, W.; Dup, B. Energy efficiency services for residential buildings: Market situation and existing potentials in the European Union. J. Clean. Prod. 2015, 109, 284-295. [CrossRef]

82. Gouveia, J.P.; Fortes, P.; Seixas, J. Projections of energy services demand for residential buildings: Insights from a bottom-up methodology. Energy 2012, 47, 430-432. [CrossRef] 
83. Weiller, C.; Neely, A. Using electric vehicles for energy services: Industry perspectives. Energy 2014, 77, 194-200. [CrossRef]

84. Xu, Q.; Cui, S.; Song, L.; Zhang, Q. Research on the Power Management Strategy of Hybrid Electric Vehicles Based on Electric Variable Transmissions. Energies 2014, 7, 934-960. [CrossRef]

85. Olivella-Rosell, P.; Bullich-Massagué, E.; Aragües-Peñalba, M.; Sumper, A.; Ottesen, S.; Vidal-Clos, J.A.; Villafáfila-Robles, R. Optimization problem for meeting distribution system operator requests in local flexibility markets with distributed energy resources. Appl. Energy 2018, 15, 881-895. [CrossRef]

86. Shivaie, M.; Ameli, M.T.; Sepasian, M.S.; Weinsier, P.D.; Vahidinasab, V. A multistage framework for reliability-based distribution expansion planning considering distributed generations by a self-adaptive global-based harmony search algorithm. Reliab. Eng. Syst. Saf. 2015, 139, 68-81. [CrossRef]

87. Logenthiran, T.; Srinivasan, D.; Shun, T.Z. Demand Side Management in Smart Grid Using Heuristic Optimization. IEEE Trans. Smart Grid 2012, 3, 1244-1252. [CrossRef]

88. Hassan, N.U.; Pasha, M.A.; Yuen, C.; Huang, S.; Wang, X. Impact of Scheduling Flexibility on Demand Profile Flatness and User Inconvenience in Residential Smart Grid System. Energies 2013, 6, 6608-6635. [CrossRef]

89. Battistelli, C.; Conejo, A.J. Optimal management of the automatic generation control service insmart user grids including electric vehicles and distributed resources. Electr. Power Syst. Res. 2014, 111, 22-31. [CrossRef]

90. Byun, J.; Hong, I.; Kang, B.; Park, S. A Smart Energy Distribution and Management System for Renewable Energy Distribution and Context-aware Services based on User Patterns and Load Forecasting. IEEE Trans. Consum. Electron. 2011, 5, 436-444. [CrossRef]

91. Pagani, G.A.; Aiello, M. Generating Realistic Dynamic Prices and Services for the Smart Grid. IEEE Syst. J. 2015, 9, 191-198. [CrossRef]

92. Ilic, M.D. Dynamic Monitoring and Decision Systems for Enabling Sustainable Energy Services. Proc. IEEE 2011, 99, 58-79. [CrossRef]

93. Houwing, M.; Ajah, A.N.; Heijnen, P.W.; Bouwmans, I.; Herder, P.M. Uncertainties in the design and operation of distributed energy resources: The case of micro-CHP systems. Energy 2008, 33, 1518-1536. [CrossRef]

94. Giuntoli, M.; Poli, D. Optimized Thermal and Electrical Scheduling of a Large Scale Virtual Power Plant in the Presence of Energy Storages. IEEE Trans. Smart Grid 2013, 4, 942-955. [CrossRef]

95. Gómez-Sanz, J.J.; García-Rodríguez, S.; Cuartero-Soler, N. Reviewing Microgrids from a Multi-Agent Systems Perspective. Energies 2014, 7, 3355-3382. [CrossRef]

96. Oh, S.-J.; Yoo, C.-H.; Chung, I.Y.; Won, D.J. Hardware-in-the-Loop Simulation of Distributed Intelligent Energy Management System for Microgrids. Energies 2013, 6, 3263-3283. [CrossRef]

97. Guan, X.; Xu, Z.; Jia, Q.-S. Energy-Efficient Buildings Facilitated by Microgrid. IEEE Trans. Smart Grid 2010, 1, 243-252. [CrossRef]

98. Ciabattoni, L.; Grisostomi, M.; Ippoliti, G.; Longhi, G. Fuzzy logic home energy consumption modeling for residential photovoltaic plant sizing in the new Italian scenario. Energy 2014, 74, 359-367. [CrossRef]

99. Foley, A.M.; Gallachóir, B.P.O.; Hur, J.; Baldick, R.; McKeogh, E.J. A strategic review of electricity systems models. Energy 2010, 35, 4522-4530. [CrossRef]

100. Gungor, V.C.; Sahin, D.; Kocak, T.; Ergut, S.; Buccella, C.; Cecati, C.; Hancke, G.P. A Survey on Smart Grid Potential Applications and Communication Requirements. IEEE Trans. Ind. Inform. 2013, 9, 28-42. [CrossRef]

101. Zidan, A.; El-Saadany, E.F. A Cooperative Multiagent Framework for Self-Healing Mechanisms in Distribution Systems. IEEE Trans. Smart Grid 2012, 3, 1525-1539. [CrossRef]

102. Xia, S.; Luo, X.; Chan, K.W. A Framework for Self-healing Smart Grid with Incorporation of Multi-Agents. Energy Procedia 2014, 61, 2123-2126. [CrossRef]

103. Colson, C.M.; Nehrir, M.H. Comprehensive Real-Time Microgrid Power Management and Control With Distributed Agents. IEEE Trans. Smart Grid 2013, 4, 617-627. [CrossRef]

104. Nguyen, T.L.; Guillo-Sansano, E.; Syed, M.H.; Nguyen, V.H.; Blair, S.M.; Reguera, L.; Tran, Q.T.; Caire, R.; Burt, G.M.; Gavriluta, C.; et al. Multi-Agent System with Plug and Play Feature for Distributed Secondary Control in Microgrid-Controller and Power Hardware-in-the-Loop Implementation. Energies 2018, 11, 3253. [CrossRef]

105. Zou, K.; Agalgaonkar, A.P.; Muttaqi, K.M.; Perera, S. An Analytical Approach for Reliability Evaluation of Distribution Systems Containing Dispatchable and Nondispatchable Renewable DG Units. IEEE Trans. Smart Grid 2014, 5, 2657-2665. [CrossRef] 
106. Kanevce, A.; Mishkovski, I.; Kocarev, L. Modeling long-term dynamical evolution of Southeast European power transmission system. Energy 2013, 57, 116-124. [CrossRef]

107. Russell, B.D.; Benner, C.L. Intelligent Systems for Improved Reliability and Failure Diagnosis in Distribution Systems. IEEE Trans. Smart Grid 2010, 1, 48-56. [CrossRef]

108. Huang, J.; Wu, N.E. Fault-tolerant placement of phasor measurement units based on control reconfigurability. Control Eng. Pract. 2013, 21,1-11. [CrossRef]

109. Chen, P.-Y.; Yang, S.; McCann, J.A. Distributed Real-Time Anomaly Detection in Networked Industrial Sensing Systems. IEEE Trans. Ind. Electron. 2015, 62, 3832-3842. [CrossRef]

110. Mahdad, B.; Srairi, K. Blackout risk prevention in a smart grid based flexible optimal strategy using Grey Wolf-pattern search algorithms. Energy Convers. Manag. 2015, 98, 411-429. [CrossRef]

111. Huang, Z.; Wang, C.; Stojmenovic, M.; Nayak, A. Balancing System Survivability and Cost of Smart Grid Via Modeling Cascading Failures. IEEE Trans. Emerg. Top. Comput. 2013, 1, 45-50. [CrossRef]

112. Hong, Y.-Y.; Chen, Y.-C. Application of algorithms and artificial-intelligence approach for locating multiple harmonics in distribution systems. IEE Proc. Gener. Transm. Distrib. 1999, 146, 325-329. [CrossRef]

113. De Oliveira, T.E.C.; Carvalho, P.M.S.; Ribeiro, P.F.; Bonatto, B.D. PV Hosting Capacity Dependence on Harmonic Voltage Distrotion in Low-Voltage Grids: Model Validation with Experimental Data. Energies 2018, 11, 465. [CrossRef]

114. Zhen, C.; Xiao, X.-Y.; Ma, C.; Wang, Y. Assessment Method of Power System Catastrophic Events Based on Electric Network Dissection and Uncertain Measure. In Proceedings of the 2011 Asia Pacific Power and Energy Engineering Conference (APPEEC), Wuhan, China, 25-28 March 2011; pp. 1-4.

115. Kamwa, I.; Samantaray, S.R.; Joos, G. Catastrophe Predictors From Ensemble Decision-Tree Learning of Wide-Area Severity Indices. IEEE Trans. Smart Grid 2010, 1, 144-158. [CrossRef]

116. Hazra, J.; Sinha, A.K. Identification of Catastrophic Failures in Power System Using Pattern Recognition and Fuzzy Estimation. IEEE Trans. Power Syst. 2009, 24, 378-387. [CrossRef]

117. Assilzadeh, H.; Levy, J.K.; Wang, X. Landslide Catastrophes and Disaster Risk Reduction: A GIS Framework for Landslide Prevention and Management. Remote Sens. 2010, 2, 2259-2273. [CrossRef]

118. Ferreira, E.F.; Barros, J.D. Faults Monitoring System in the Electric Power Grid with Scalability to Detect Natural/Environmental Catastrophes. Int. J. Therm. Environ. Eng. 2018, 16, 37-45. [CrossRef]

119. Biswas, S.S.; Srivastava, A.K.; Park, J.S.; Castaneda, J. Tool for testing of phasor measurement units: PMU performance analyzer. IET Gener. Transm. Distrib. 2015, 9, 154-163. [CrossRef]

120. Grant, J.; Eltoukhy, M. Short-Term Electrical Peak Demand Forecasting in a Large Government Building Using Artificial Neural Networks. Energies 2014, 7, 1935-1953. [CrossRef]

121. Hernández, L.; Baladrón, C.; Aguiar, J.M.; Carro, B.; Sanchez-Esguevillas, A.J.; Lloret, J.; Massana, J. A Survey on Electric Power Demand Forecasting: Future Trends in Smart Grids, Microgrids and Smart Buildings. IEEE Commun. Surv. Tutor. 2014, 16, 1460-1495. [CrossRef]

122. Siano, P.; Cecati, C.; Yu, H.; Kolbusz, J. Real Time Operation of Smart Grids via FCN Networks and Optimal Power Flow. IEEE Trans. Ind. Inform. 2012, 8, 944-952. [CrossRef]

123. Chang, H.-H. Non-Intrusive Demand Monitoring and Load Identification for Energy Management Systems Based on Transient Feature Analyses. Energies 2012, 5, 4569-4589. [CrossRef]

124. Bruneo, D.; Cucinotta, A.; Minnolo, A.L.; Puliafito, A.; Scarpa, M. Energy Management in Industrial Plants. Computers 2012, 1, 24-40. [CrossRef]

125. Arghira, N.; Hawarah, L.; Ploix, S.; Jacomino, M. Prediction of appliances energy use in Smart homes. Energy 2012, 48, 128-134. [CrossRef]

126. Liao, C.-S.; Hsieh, T.-J.; Guo, X.-C.; Liu, J.-H.; Chu, C.-C. Hybrid search for the optimal PMU placement problem on a power grid. Eur. J. Oper. Res. 2015, 243, 985-994. [CrossRef]

127. Pillai, J.R.; Heussen, K.; Ostergaard, P.A. Comparative analysis of hourly and dynamic power balancing models for validating future energy scenarios. Energy 2011, 36, 3233-3243. [CrossRef]

128. Faria, P.; Vale, Z. Demand response in electrical energy supply: An optimal real time pricing approach. Energy 2011, 36, 5374-5384. [CrossRef]

129. Vallée, F.; Klonari, V.; Lisiecki, T.; Durieux, O.; Moiny, F.; Lobry, J. Development of a probabilistic tool using Monte Carlo simulation and smart meters measurements for the long term analysis of low voltage distribution grids with photovoltaic generation. Electr. Power Energy Syst. 2013, 53, 468-477. [CrossRef] 
130. Flores, R.J.; Shaffer, B.P.; Brouwer, J. Dynamic distributed generation dispatch strategy for lowering the cost of building energy. Appl. Energy 2014, 123, 196-208. [CrossRef]

131. Azzopardi, B.; Gabriel-Buenaventura, A. Feasibility assessment for high penetration of distributed photovoltaics based on net demand planning. Energy 2014, 76, 233-240. [CrossRef]

132. Shafie-Khah, M.; Moghaddam, M.P.; Sheikh-El-Eslami, M.K.; Rahmani-Andebil, M. Modeling of interactions between market regulations and behavior of plug-in electric vehicle aggregators in a virtual power market environment. Energy 2012, 40, 139-150. [CrossRef]

133. Welsch, M.; Howells, M.; Brazilian, M.; DeCarolis, J.F.; Hermann, S.; Rogner, H.H. Modelling elements of Smart Grids-Enhancing the OSeMOSYS (Open Source Energy Modelling System) code. Energy 2012, 46, 337-350. [CrossRef]

134. Yuan, J.; Xu, Y.; Kang, J.; Zhang, X.; Hu, Z. Nonlinear integrated resource strategic planning model and case study in China's power sector planning. Energy 2014, 67, 27-40. [CrossRef]

135. Wang, J.; Zhong, H.; Xia, Q.; Kang, C. Optimal Planning Strategy for Distributed Energy Resources Considering Structural Transmission Cost Allocation. IEEE Trans. Smart Grid 2018, 9, 5236-5248. [CrossRef]

136. Maass, H.; Çakmak, H.K.; Suess, W.; Quinte, A.; Jakob, W.; Stucky, K.; Kuehnapfel, U.G. First Evaluation Results Using the New Electrical Data Recorder for Power Grid Analysis. IEEE Trans. Instrum. Meas. 2013, 62, 2384-2390. [CrossRef]

137. Kim, Y.-J.; Thottan, M.; Kolesnikov, V.; Lee, W. A Secure Decentralized Data-Centric Information Infrastructure for Smart Grid. IEEE Commun. Mag. 2010, 48, 58-65. [CrossRef]

138. Werley, E.; Saavedra, O.S.; Carmona, O.A.; Nunes, A. Detection and Identification of Abnormalities in Customer Consumptions in Power Distribution Systems. IEEE Trans. Power Deliv. 2001, 26, 2436-2442.

139. Lu, Z.; Wen, Y. Distributed Algorithm for Tree-Structured Data Aggregation Service Placement in Smart Grid. IEEE Syst. J. 2014, 8, 553-561.

140. Sancho-Asensio, A.; Navarro, J.; Arrieta-Salinas, I.; Armendáriz-Íñigo, J.E.; Jímenez-Ruano, V.; Zaballos, A.; Golobardes, E. Improving data partition schemes in Smart Grids via clustering data streams. Expert Syst. Appl. 2014, 41, 5832-5842. [CrossRef]

141. Santodomingo, R.; Rohjans, S.; Uslar, M.; Rodríguez-Mondéjar, J.A.; Sanz-Bobi, M.A. Ontology matching system for future Energy smart grids. Eng. Appl. Artif. Intell. 2014, 32, 242-257. [CrossRef]

142. Liu, J.; Li, X.; Liu, D.; Liu, H.; Mao, P. Study on Data Management of Fundamental Model in Control Center for Smart Grid Operation. IEEE Trans. Smart Grid 2011, 2, 573-579. [CrossRef]

143. Macedo, M.N.Q.; Galo, J.J.M.; Almeida, L.A.L.; Lima, A.C.C. Typification of load curves for DSM in Brazil for s smart grid environment. Electr. Power Energy Syst. 2015, 67, 216-221. [CrossRef]

144. Angioni, A.; Lu, S.; Hooshyar, H.; Cairo, I.; Repo, S.; Ponci, F.; Della Giustina, D.; Kulmala, A.; Dedè, A.; Monti, A.; et al. A distributed automation architecture for distribution networks, from design to implementation. Sustain. Energy Grids Netw. 2018, 15, 3-13. [CrossRef]

145. Chen, C.; Nagananda, K.G.; Xiong, G.; Kishore, S.; Snyder, L.V. A Communication-Based Appliance Scheduling Scheme for Consumer-Premise Energy Management Systems. IEEE Trans. Smart Grid 2013, 4, 56-65. [CrossRef]

146. Liu, C.-X.; Zeng, Q.A.; Liu, Y. A Dynamic Load Control Scheme for Smart Grid Systems. Energy Procedia 2011, 12, 200-205. [CrossRef]

147. Calderaro, V.; Galdi, V.; Lamberti, F.; Piccolo, A. A Smart Strategy for Voltage Control Ancillary Service in Distribution Networks. IEEE Trans. Power Syst. 2015, 30, 494-502. [CrossRef]

148. Li, D.; Jayaweera, S.K. Distributed Smart-Home Decision-Making in a Hierarchical Interactive Smart Grid Architecture. IEEE Trans. Parallel Distrib. Syst. 2015, 26, 75-84. [CrossRef]

149. Chen, Z.; Wu, L.; Li, Z. Electric Demand Response Management for Distributed Large-Scale Internet Data Centers. IEEE Trans. Smart Grid 2014, 5, 651-661. [CrossRef]

150. Queiroz, L.M.O.; Lyra, C. Adaptive Hybrid Genetic Algorithm for Technical Loss Reduction in Distribution Networks Under Variable Demands. IEEE Trans. Power Syst. 2009, 24, 445-453. [CrossRef]

151. Queiroz, L.M.O.; Roselli, M.A.; Cavellucci, C.; Lyra, C. Energy Losses Estimation in Power Distribution Systems. IEEE Trans. Power Syst. 2012, 27, 1879-1887. [CrossRef]

152. Spiric, J.V.; Docic, M.B.; Stankovic, S.S. Fraud detection in registeredelectricity time series. Electr. Power Energy Syst. 2015, 71, 42-50. [CrossRef] 
153. Aranha, E.A.C.; Coelho, J. Probabilistic methodology for Technical and Non-Technical Losses estimation in distribution system. Electr. Power Syst. Res. 2013, 97, 93-99. [CrossRef]

154. Monedero, I.; Biscarri, F.; León, C.; Guerrero, J.I.; Biscarri, J.; Millán, R. Detection of frauds and other non-technical losses in a power utility using Pearson coefficient, Bayesian networks and cedision trees. Electr. Power Energy Syst. 2012, 34, 90-98. [CrossRef]

155. Shekara, S.; Wang, L.; Devabhaktuni, V.; Green, R.C. High performance computing for detection of electricity theft. Electr. Power Energy Syst. 2013, 47, 21-30.

156. Lin, C.-H.; Chen, S.-J.; Kuo, C.-L.; Chen, J.-L. Non-Cooperative Game Model Applied to and Advanced Metering Infrastructure for Non-Technical Loss Screening in Micro-Distribution Systems. IEEE Trans. Smart Grid 2014, 5, 2468-2469. [CrossRef]

157. León, C.; Biscarri, F.; Monedero, I.; Guerrero, J.I.; Biscarri, J.; Millán, R. Integrated expert system applied to the analysis of non-technical losses in power utilities. Expert Syst. Appl. 2011, 38, 10274-10285. [CrossRef]

158. Guerrero, J.I.; León, C.; Monedero, I.; Biscarri, F.; Biscarri, J. Improving Knowledge-Based Systems with statiscal techniques, text mining, and neural networks for non-technical loss detection. Knowl.-Based Syst. 2014, 71, 376-388. [CrossRef]

159. Nagi, J.; Yap, K.S.; Tiong, S.K.; Ahmed, S.K.; Mohamad, M. Nontechnical Loss Detection for Metered Customers in Power Utility Using Support Vector Machines. IEEE Trans. Power Deliv. 2010, 25, 1162-1171. [CrossRef]

160. Nagi, J.; Yap, K.S.; Tiong, S.K.; Ahmed, S.K.; Nagi, F. Improving SVM-Based Nontechnical Loss Detection in Power Utility Using the Fuzzy Inference System. IEEE Trans. Power Deliv. 2011, 26, 1284-1285. [CrossRef]

161. Ramos, C.C.O.; Souza, A.N.; Chiachia, G.; Falcao, A.X.; Papa, J.P. A novel algorithm for feature selection using Harmony Search and its application for non-technical losses detection. Comput. Electr. Eng. 2011, 37, 886-894. [CrossRef]

162. Guerrero, J.I.; Monedero, I.; Biscarri, F.; Biscarri, J.; Millán, R.; León, C. Non-Technical Losses Reduction by Improving the Inspections Accuracy in a Power Utility. IEEE Trans. Power Syst. 2018, 33, 1209-1218. [CrossRef]

163. Wang, H.; Zhang, G.; Guo, Z.; Wang, J.; Cai, X. Application of Electronic Transformers in Digital Sustation. In Proceedings of the 2008 POWERCON Joint International Conference on Power System Technology and IEEE Power India Conference, New Delhi, India, 12-15 October 2008; pp. 1-5.

164. Kucuksari, S.; Karady, G.G. Experimental Comparasion of Conventional and Optical Current Transformers. IEEE Trans. Power Deliv. 2010, 25, 2455-2463. [CrossRef]

165. Li, H.; Wang, L. Research on Technologies in Smart Substation. Energy Procedia 2011, 12, 113-119. [CrossRef]

166. Amin, M. Toward self-healing energy infrastructure systems. IEEE Comput. Appl. Power 2002, 14, $20-28$. [CrossRef]

167. Tang, J.; Zhou, J.; Zhang, X.; Liu, F. A Transformer Partial Discharge Measurement System Based on Fluorescent Fiber. Energies 2012, 5, 1490-1502. [CrossRef]

168. Lim, I.-H.; Sidhu, T.S. Design of a Backup IED for IEC 61850-Based Substation. IEEE Trans. Power Deliv. 2013, 28, 2048-2055. [CrossRef]

169. Kapareliotis, E.S.; Drakakis, K.E.; Dimitriadis, H.P.K.; Capsalis, C.N. Fault Recognition on Power Networks via SNR Analysis. IEEE Trans. Power Deliv. 2009, 24, 2428-2433. [CrossRef]

170. You, H.; Vittal, V.; Zhong, Y. Self-Healing in Power Systems: An Approach Using Islanding and Rate of Frequency Decline-Based Load Shedding. IEEE Trans. Power Syst. 2003, 18, 174-181.

171. Shen, M.; Venkatasubramanian, V.; Abi-Samra, N.; Sobajic, D. A New Framework for Estimation of Generator Dynamic Parameters. IEEE Trans. Power Syst. 2000, 15, 756-763. [CrossRef]

172. Guo, S.; Norris, S.; Bialek, J. Adaptive Parameter Estimation of Power System Dynamic Model Using Modal Information. IEEE Trans. Power Syst. 2014, 29, 2854-2861. [CrossRef]

173. Ariff, M.A.M.; Pal, B.C.; Singh, A.K. Estimating Dynamic Model Parameters for Adaptive Protection and Control in Power System. IEEE Trans. Power Syst. 2015, 30, 829-839. [CrossRef]

174. Clavel, F.; Savary, E.; Angays, P.; Vieux-Melchior, A. Integration of a New Standard: A network simulator of IEC 61850 architectures for electrical substation. IEEE Ind. Appl. Mag. 2014, 21, 41-48. [CrossRef]

175. Giustina, D.D.; Ferrari, P.; Flammini, A.; Rinaldi, S.; Sisinni, E. Automation of Distribution Grids With IEC 61850: A First Approach Using Broadband Power Line Communication. IEEE Trans. Instrum. Meas. 2013, 62, 2372-2383. [CrossRef] 
176. Zhu, L.; Shi, D.; Wang, P. IEC 61850-Based Information Model and Configuration Description of Communication Network in Substation Automation. IEEE Trans. Power Deliv. 2014, 29, 97-107. [CrossRef]

177. Mercurio, A.; Di Giorgio, A.; Cioci, P. Open-Source Implementation of Monitoring and Controlling Services for EMS/SCADA Systems by Means of Web Services- IEC 61850 and IEC 61970 Standards. IEEE Trans. Power Deliv. 2009, 24, 1148-1153. [CrossRef]

178. Lee, B.; Kim, D.-K.; Yang, H.; Jang, H.; Hong, D.; Falk, H. Unifying Data Types of IEC 61850 and CIM. IEEE Trans. Power Syst. 2015, 30, 448-456. [CrossRef]

179. Parent, G.; Rossi, M.; Duchesne, S.; Dular, P. Determination of Partial Discharge Inception Voltage and Location of Partial Discharges by Means of Paschen's Theory and FEM. IEEE Trans. Magn. 2019. [CrossRef]

180. Abubakar, A.; Steward, B.G.; McMeekin, S.G. Application of an ensemble neural network for classifying partial discharge patterns. Electr. Power Syst. Res. 2014, 110, 154-162. [CrossRef]

181. Boczar, T.; Borucki, S.; Cichón, A.; Zmarzly, D. Application Possibilities of Artificial Neural Networks for Recognizing Partial Discharges Measured by the Acoustic Emission Method. IEEE Trans. Dielectr. Electr. Insul. 2009, 16, 214-223. [CrossRef]

182. Oyama, M.; Hanai, E.; Aoyagi, H.; Hurase, H.; Ohshima, I.; Menju, S. Development of Detection and Diagnostic Techniques for Partial Discharges in GIS. IEEE Trans. Power Deliv. 1994, 9, 811-818. [CrossRef]

183. Cavallini, A.; Montanari, G.C.; Tozzi, M.; Chen, X. Diagnostic of HVDC Systems Using Partial Discharges. IEEE Trans. Dielectr. Electr. Insul. 2011, 18, 275-284. [CrossRef]

184. Álvarez, F.; Garnacho, F.; Ortego, J.; Sánchez-Urán, M.A. Application of HFCT and UHF Sensors in On-Line Partial Discharge Measurements for Insulation Diagnosis of High Voltage Equipment. Sensors 2015, 15, 7360-7387. [CrossRef] [PubMed]

185. Shafiq, M.; Hussain, G.A.; Kütt, L.; Elkalashy, N.I.; Lehtonen, M. Partial discharge diagnostic system for smart distribution networks using directionally calibrated induction sensors. Electr. Power Syst. Res. 2015, 119, 447-461. [CrossRef]

186. Chen, W.; Chen, X.; Peng, S.; Li, J. Canonical Correlation Between Partial Discharges and Gas Formation in Transformer Oil Paper Insulation. Energies 2012, 5, 1081-1097. [CrossRef]

187. Seo, I.-J.; Khan, U.A.; Hwang, J.-S.; Lee, J.-G.; Koo, J.-Y. Identification of Insulation Defects Based on Chaotic Analysis of Partial Discharge in HVDC Superconducting Cable. IEEE Trans. Appl. Supercond. 2015, 25, 5402005. [CrossRef]

188. Strachan, S.M.; Rudd, S.; McArthur, S.D.J.; Judd, M.D. Knowledge-Based Diagnosis of Partial Discharges in Power Transformers. IEEE Trans. Dielectr. Electr. Insul. 2008, 15, 259-268. [CrossRef]

189. Bengtsson, T.; Lindell, E.; Hammarström, T. Stochastic Detection of Partial Discharges. IEEE Trans. Dielectr. Electr. Insul. 2013, 20, 2203-2211. [CrossRef]

190. Li, C.-R.; Ma, G.-M.; Qi, B.; Zhang, G.-J.; Su, Q. Condition Monitoring and Diagnosis of High-Voltage Equipment in China-Recent Progress. IEEE Electr. Insul. Mag. 2013, 29, 71-78. [CrossRef]

191. Brown, R.E.; Humphrey, B.G. Asset Management for Transmission and Distribution. IEEE Power Energy Mag. 2005, 3, 39-45. [CrossRef]

192. Prince, S. Customers: The "New" Strategic Asset for Utilities. Electr. J. 2005, 18, 85-90. [CrossRef]

193. Park, S.; Lee, E.; Yu, W.; Lee, H.; Shin, J. State estimation for Supervisory Monitoring of Substations. IEEE Trans. Smart Grid 2013, 4, 406-410. [CrossRef]

194. Ma, H.; Saha, T.K.; Ekanayake, C.; Martin, D. Smart Transformer for Smart Grid-Intelligent Framework and Techniques for Power Transformer Asset management. IEEE Trans. Smart Grid 2015, 6, 1026-1034. [CrossRef]

195. Sun, Y.; Wang, X.; Bie, Z.; Wang, X. Characteristics Analysis and Risk Modeling of Ice Flashover Fault in Power Grids. IEEE Trans. Power Deliv. 2012, 27, 1301-1312. [CrossRef]

196. Dashti, R.; Afsharnia, S. Decisions, Decisions. IEEE Power Energy Mag. 2014, May//une, 96-108. [CrossRef]

197. Ochoa, L.F.; Dent, C.J.; Harrison, G.P. Distribution Network Capacity Assessment: Variable DG and Active Networks. IEEE Trans. Power Syst. 2010, 25, 87-95. [CrossRef]

198. Linares, P. Multiple Criteria Decision Making and Risk Analysis as Risk Management Tools for Power Systems Planning. IEEE Trans. Power Syst. 2002, 17, 895-900. [CrossRef]

199. Popovic, D.S.; Popovic, Z.N. A Risk Management Procedure for Supply Restoration in Distribution Networks. IEEE Trans. Power Syst. 2004, 19, 221-228. [CrossRef]

200. Rocchetta, R.; Bellani, L.; Compare, M.; Zio, E.; Patelli, E. A reinforcement learning framework for optimal operation and maintenance of power grids. Appl. Energy 2019, 241, 291-301. [CrossRef] 
201. Scutariu, M.; Albert, H. Corrective Maintenance Timetable in Restructured Distribution Environment. IEEE Trans. Power Deliv. 2007, 22, 650-657. [CrossRef]

202. Hilber, P.; Miranda, V.; Matos, M.A.; Bertling, L. Multiobjective Optimization Applied to Maintenance Policy for Electrical Networks. IEEE Trans. Power Syst. 2007, 22, 1675-1682. [CrossRef]

203. Yumbe, Y.; Hasegawa, T.; Furukawa, N. Optimization Method for Inspection Scheduling of Power Distribution Facilities. IEEE Trans. Power Deliv. 2013, 28, 1558-1565. [CrossRef]

204. Tajnsek, V.; Pihler, J.; Roser, M. Advanced Logistical Systems for the Maintenance of Overhead Distribution Lines Through DCC With the Use of Laser Monitoring. IEEE Trans. Power Deliv. 2011, 26, 1337-1343. [CrossRef]

205. Yang, F.; Kwan, C.M.; Chang, C.S. Multiobjective Evolutionary Optimization of Substation Maintenance Using Decision-Varying Markov Model. IEEE Trans. Power Syst. 2008, 23, 1328-1335. [CrossRef]

206. Heo, J.-H.; Kim, M.-K.; Park, G.-P.; Toon, Y.T.; Park, J.K.; Lee, S.-S.; Kim, D.-H. A Reliability-Centered Approach to and Optimal Maintenance Strategy in Transmission Systems Using a Genetic Algorithm. IEEE Trans. Power Deliv. 2011, 26, 2171-2179. [CrossRef]

207. Madan, S.; Bollinger, K.E. Applications of artificial intelligence in power systems. Electr. Power Syst. Res. 1997, 41, 117-131. [CrossRef]

208. Burt, G.M.; McDonald, J.R.; Spiller, J.; Brooke, D.; Samwell, R. Intelligent On-Line Decision Support for Distribution System Control and Operation. IEEE Trans. Power Syst. 1995, 10, 1820-1827. [CrossRef]

209. Mohagheghi, S. Integrity Assessment Scheme for Situational Awareness in Utility Automation Systems. IEEE Trans. Smart Grid 2014, 5, 592-601. [CrossRef]

210. Alam, M.J.E.; Muttaqi, K.M.; Sutanto, D. A SAX-Based Advanced Computational Tool for Assessment of Clustered Rooftop Solar PV Impacts on LV and MV Networks in Smart Grid. IEEE Trans. Smart Grid 2013, 4, 577-585. [CrossRef]

211. Jimenez, Y.; Duarte, C.; Petit, J.; Carrillo, G. Feature extraction for nonintrusive load monitoring based on S-Transform. In Proceedings of the 2014 Clemson University Power Systems Conference, Clemson, SC, USA, 11-14 March 2014; pp. 1-5.

212. Radhakrishnan, B.M.; Srinivasan, D. A multi-agent based distributed energy management scheme for smart grid applications. Energy 2016, 103, 192-294. [CrossRef]

213. Sianaki, O.A.; Hussain, O.; Dillon, T.; Tabesh, A.R. Intelligent Decision Support System for Including Consumers' Preferences in Residential Energy Consumption in Smart Grid. In Proceedings of the 2010 Second International Conference on Computational Intelligence, Modelling and Simulation (CIMSiM), Bali, Indonesia, 28-30 September 2010; pp. 154-159.

214. Liu, Y. Seasonal relationship of peak demand and energy impacts of energy efficiency measures-a review of evidence in the electric energy efficiency programmes. Energy Effic. 2016, 9, 1015-1035. [CrossRef]

215. Gellings, C.W.; Samotyj, M. Smart Grid as advanced technology enabler of demand response. Energy Effic. 2013, 6, 685-694. [CrossRef]

216. Janjic, A.; Savic, S.; Janackovic, G.; Stankovic, M.; Velimirovic, L. Multi-criteria assessment of the smart grid efficiency using the fuzzy analytic hierarchy process. Electron. Energ. 2016, 29, 631-646. [CrossRef]

217. Pedrycz, W.; Chen, S.-M. Granular Computing and Decision-Making; Springer: Cham, Switzerland, 2015.

218. Wang, J.-J.; Jung, Y.-Y.; Zhang, C.-F.; Zhao, J.-H. Review on multi-criteria decision analysis aid in sustainable energy decision-making. Renew. Sustain. Energy Rev. 2009, 13, 2263-2278. [CrossRef]

219. Kumar, A.; Sah, B.; Singh, A.R.; Deng, Y.; He, X.; Kumar, P.; Bansal, R.C. A review of multi criteria decision making (MCDM) towards sustainable renewable energy development. Renew. Sustain. Energy Rev. 2017, 69, 596-609. [CrossRef]

220. Mondal, A.; Misra, S.; Obaidat, M.S. Distributed Home Energy Management System With Storage in Smart Grid Using Game Theory. IEEE Syst. J. 2017, 11, 1857-1866. [CrossRef]

221. Ansari, J.; Gjolami, A.; Kazemi, A. Multi-agent systems for reactive power control in smart grids. Electr. Power Energy Syst. 2016, 83, 411-425. [CrossRef]

222. Shadmand, M.B.; Balog, R.S. Multi-Objective Optimization and Design of Photovoltaic-Wind Hybrid System for Community Smart DC Microgrid. IEEE Trans. Smart Grid 2014, 5, 2635-2643. [CrossRef]

223. Janjic, A.; Savic, S.; Velimirovic, L.; Nikolic, V. Renewable energy integration in smart grids-multicriteria assessment using the fuzzy analytical hierarchy process. Turk. J. Electr. Eng. Comput. Sci. 2015, 23, 1896-1912. [CrossRef] 
224. Laaksonen, H. New Multi-criteria-based Algorithm for Islanding Detection in Smart Grids. In Proceedings of the 3rd IEEE PES Innovative Smart Grid Technologies Europe (ISGT Europe), Berlin, Germany, 14-17 October 2012; pp. 1-8.

225. Matulaitis, V.; Straukaité, G.; Azzopardi, B.; Martínez-Cesena, E.A. Multi-criteria decision making for PV deployment on a multinational level. Sol. Energy Mater. Sol. Cells 2016, 156, 122-127. [CrossRef]

226. Padhee, M.; Dash, P.K.; Krishnanand, K.R.; Rout, P.K. A Fas Gauss-Newton Algorithm for Islanding Detection in Distributed Generation. IEEE Trans. Smart Grid 2012, 3, 1181-1191. [CrossRef]

227. Pouresmaeil, E.; Montesinos-Miracle, D.; Gomis-Bellmunt, O.; Bergas-Jané, J. A multi-objective control strategy for grid connection of DG (distributed generation) resources. Energy 2010, 35, 5022-5030. [CrossRef]

228. Oh, S.-C.; Hildreth, A.J. Decisions on Energy Demand Response Option Contracts in Smart Grids Based on Activity-Based Costing and Stochastic Programming. Energies 2013, 6, 425-443. [CrossRef]

229. Coury, D.V.; Delbem, A.C.B.; Rodrigues, J.; Oleskovicz, M.; Simoes, E.V.; Barbosa, D.; da Silva, T.V. Frequency Estimation Using a Genetic Algorithm With Regularization Implemented in FPGAs. IEEE Trans. Smart Grid 2012, 3, 1353-1361. [CrossRef]

230. Zhang, G.; Dai, S.; Song, N.; Zhu, Z.; Zhang, J.; Guo, W.; Zhang, D.; Zhang, Z.; Xiao, L.; Lin, L. The Construction Progress of a High-Tc Superconducting Power Substation in China. IEEE Trans. Appl. Supercond. 2011, 21, 2824-2827. [CrossRef]

231. Geschiere, A.; Willén, D.; Melnik, I.; Piga, E.; Barendregt, P. HTS Cables: Dealing with the Challenges of DER. In Proceedings of the 20th International Conference on Electricity Distribution, Prague, Czech Republic, 8-11 June 2009; pp. 1-4.

232. Wang, Y.; Zheng, Y.; Liu, H.; Dai, S.; Zhang, H.; Guan, X.; Teng, Y.; Zhao, L.; Xue, J.; Lin, L. A Novel Approach for Design of DC HTS Cable. IEEE Trans. Appl. Supercond. 2011, 21, 1042-1045. [CrossRef]

233. Pi, W.; Yang, Q.; Wang, T.; Peng, C.; Wang, Y.; Shi, Q.; Dong, J. Insulation Design and Simulation for Three-Phase Concentric High-Temperature Superconducting Cable Under 10-kV Power System. IEEE Trans. Appl. Supercond. 2019, 29. [CrossRef]

234. Xiao, Y.; Song, Y.H.; Liu, C.-C.; Sun, Y.Z. Available Transfer Capability Enhancement Using FACTS Devices. IEEE Trans. Power Syst. 2003, 18, 305-312. [CrossRef]

235. Cvetkovic, M.; Ilic, M.D. Ectropy-Based Nonlinear Control of FACTS for Transient Stabilization. IEEE Trans. Power Syst. 2014, 29, 3012-3020. [CrossRef]

236. Lashkar, A.; Kazemi, A.; Niaki, S.A.N. Multiobjective Optimal Location of FACTS Shunt-Series Controllers for Power System Operation Planning. IEEE Trans. Power Deliv. 2012, 27, 481-490. [CrossRef]

237. Ramesh, M.; Swathi, I.; Laxmi, A.J. Stability Enhancement of HVDC System Using Fuzzy Based STATCOM. In Proceedings of the 2012 AASRI Conference on Power and Energy Systems, Hong Kong, China, 4-5 September 2012; pp. 205-215.

238. Ghahremani, E.; Kamwa, I. Optimal Placement of Multiple-Type FACTS Devices to Maximize Power System Loadability Using a Generic Graphical User Interface. IEEE Trans. Power Syst. 2013, 28, 764-778. [CrossRef]

239. Tuzikova, V.; Tlusty, J.; Muller, Z. A Novel Power Losses Reduction Method Based on a Particle Swarm Optimization Algorithm Using STATCOM. Energies 2018, 11, 2851. [CrossRef]

240. Ravadanegh, S.N.; Roshanagh, R.G. A heuristic algorithm for optimal multistage sizing, siting and timing of MV distribution substations. Electr. Power Syst. Res. 2013, 105, 134-141. [CrossRef]

241. Leborgne, R.C.; de Oliveira, T.C.; de Carvalho, J.M.; de Oliveira, J.F.; Bollen, M.H.J. New approach for power lines performance estimation based on load variation due to voltage sags. Electr. Power Syst. Res. 2012, 83, 35-40. [CrossRef]

242. Salmerón, P.; Vázquez, J.R. Practical Design of a Three-Phase Active Power-Line Conditioner Controlled by Artificial Neural Networks. IEEE Trans. Power Deliv. 2005, 20, 1037-1044. [CrossRef]

243. Corsi, S.; Pozzi, M. A Multivariable New Control Solution for Increased Long Lines Voltage Restoration Stability During Black Startup. IEEE Trans. Power Syst. 2003, 18, 1133-1141. [CrossRef]

244. El-Fouly, T.H.M.; Zeineldin, H.H.; El-Saadany, E.F.; Salama, M.M.A. A new optimization model for distribution substation siting, sizing, and timing. Electr. Power Energy Syst. 2008, 30, 308-315. [CrossRef]

245. Esmaeeli, M.; Kazemi, A.; Shayanfar, H.A.; Haghifam, M.-R. Multistage distribution substation planning considering reliability and growth of energy demand. Energy 2015, 84, 357-364. [CrossRef]

246. Akbari, T.; Heidarizadeh, M.; Siab, M.A.; Abroshan, M. Towards integrated planning: Simultaneous transmission and substation expansion planning. Electr. Power Syst. Res. 2012, 86, 131-139. [CrossRef] 
247. Kabir, G.; Sumi, R.S. Power substation location selection using fuzzy analytic hierarchy process and PROMETHEE: A case study from Bangladesh. Energy 2014, 72, 717-730. [CrossRef]

248. Khoshsolat, S.A.; Aziz, N.A.; Ismail, N.; Adam, N. Repositioning of Electric Distribution Substations Using Fuzzy Decision Making. In Proceedings of the 2011 2nd International Conference on Advances in Energy Engineering (ICAEE 2011), Bangkok, Thailand, 27-28 December 2011; pp. 476-482.

249. Wang, Z.; Bian, S.; Liu, Y.; Liu, Z. The load characteristics classification and synthesis of substations in large area power grid. Electr. Power Energy Syst. 2013, 48, 71-82. [CrossRef]

250. Rodrigues, E.M.G.; Godina, R.; Santos, S.F.; Bizuayehu, A.W.; Contreras, J.; Catalao, J.P.S. Energy storage systems supporting increased penetration of renewables in islanded systems. Energy 2014, 75, 265-280. [CrossRef]

251. Adhau, S.P.; Moharil, R.M.; Adhau, P.G. Estimation of Micro Hydro Power Plant Capacity From Potential Sites. In Proceedings of the 2012 IEEE International Conference on Power Electronics, Drivers and Energy Systems, Bengaluru, India, 16-19 December 2012; pp. 1-4.

252. Payyala, S.L.; Green, T.C. Sizing of Distributed Generation Plant Through Techno-Economic Feasibility Assessment. In Proceedings of the 2006 IEEE Power Engineering Society General Meeting, Montreal, QC, Canada, 18-22 June 2006; pp. 1-8.

253. Cornalino, E.; Coppes, E.; Chaer, R. Modeling and simulation of the electricity generation system of Uruguay in 2015 with high penetration of wind power. In Proceedings of the 2012 Sixth IEEE/PES Transmission and Distribution: Latin America Conference and Exposition, Montevideo, Uruguay, 3-5 September 2012; pp. 1-5.

254. Seixas, M.; Melício, R.; Mendes, V.M.F. Simulation of rectifier voltage malfunction on OWECS, four-level converter, HVDC light link: Smart grid context tool. Energy Convers. Manag. 2015, 97, 140-153. [CrossRef]

255. Lave, M.; Kleissl, J.; Ellis, A.; Mejia, F. Simulated PV Power Plant Variability: Impact of Utility-imposed Ramp Limitations in Puerto Rico. In Proceedings of the 2013 IEEE 39th Photovoltaic Specialists Conference (PVSC), Tampa, FL, USA, 16-21 June 2012; pp. 1817-1821.

256. Pavkovic, D.; Hoic, M.; Deur, J.; Petric, J. Energy storage systems sizing study for a high-altitude wind energy application. Energy 2014, 76, 91-103. [CrossRef]

257. Zhao, P.; Wang, M.; Wang, J.; Dai, Y. A preliminary dynamic behaviors analysis of a hybrid energy storage system based on adiabatic compressed air energy storage and flywheel energy storage system for wind power application. Energy 2015, 84, 825-839. [CrossRef]

258. Gitizadeh, M.; Fakharzadegan, H. Battery capacity determination with respect to optimized energy dispatch schedule in grid-connected photovoltaic (PV) systems. Energy 2014, 65, 665-674. [CrossRef]

259. Yoo, J.; Park, B.; An, K.; Al-Ammar, E.A.; Khan, Y.; Hur, K.; Kim, J.H. Look-Ahead Energy Management of a Grid-Connected Residential PV System with Energy Storage under Time-Based rate Programs. Energies 2012, 5, 1116-1134. [CrossRef]

260. Elsheikh, A.M.; Sharshir, S.W.; Elaziz, M.A.; Kabeel, A.E.; Guilan, W.; Haiou, Z. Modeling of solar energy systems using artificial neural network: A comprehensive review. Sol. Energy 2019, 622-639. [CrossRef]

261. Barnes, A.K.; Balda, J.C.; Escobar-Mejía, A. A Semi-Markov Model for Control of Energy Storage in Utility Grids and Microgrids With PV Generation. IEEE Trans. Sustain. Energy 2015, 6, 546-556. [CrossRef]

262. Brekken, K.A.; Yokochi, A.; von Jouanne, A.; Yen, Z.Z.; Hapke, H.M.; Halamay, D.A. Optimal Energy Storage Sizing and Control for Wind Power Applications. IEEE Trans. Sustain. Energy 2011, 2, 69-77. [CrossRef]

263. Mahdianpoor, F.M.; Hooshmand, R.A.; Ataei, M. A New Approach to Multifunctional Dynamic Voltage Restorer Implementation for Emergency Control in Distribution Systems. IEEE Trans. Power Deliv. 2011, 26, 882-890. [CrossRef]

264. Boutsika, T.N.; Papathanassiou, S.A. Short-circuit calculations in networks with distributed generation. Electr. Power Syst. Res. 2008, 78, 1181-1191. [CrossRef]

265. Djukanovic, M.; Bekut, D.; Sobajic, D.J.; Pao, Y.H. Neural network based calculation of short-circuit currents in three-phase systems. Electr. Power Syst. Res. 1992, 24, 49-53. [CrossRef]

266. Kabir, M.A.; Mahbub, U. Synchronous Detection and Digital control of Shunt Active Power Filter in Power Quality Improvement. In Proceedings of the 2011 IEEE Power and Energy Conference at Illinois, Champaign, IL, USA, 25-26 February 2011; pp. 1-5.

267. López-Martín, V.M.; Azcondo, F.J.; Pigazo, A. Power Quality Enhancement in Residential Smart Grids Through Power Factor Correction Stages. IEEE Trans. Ind. Electron. 2018, 65, 8553-8564. [CrossRef] 
268. Hua, L.; Wang, J.; Zhou, C. Adaptive Electric Vehicle Charging Coordination on Distribution Network. IEEE Trans. Smart Grid 2014, 5, 2666-2675.

269. Nunes, P.; Farias, T.; Brito, M.C. Day charging electric vehicles with excess solar electricity for a sustainable energy system. Energy 2015, 80, 263-274. [CrossRef]

270. Zhu, J.; Jiang, P.; Gu, W.; Seng, W.; Meng, X.; Gao, J. Finite Action-Set Learning Automata for Economic Dispatch Considering Electric Vehicles and Renewable Energy Resources. Energies 2014, 7, 4629-4647. [CrossRef]

271. Wang, X.; Shahidehpour, M.; Jiang, C.; Li, Z. Coordinated Planning Strategy for Electric Vehicle Charging Stations and Coupled Traffic-Electric Networks. IEEE Trans. Power Syst. 2019, 34, 268-279. [CrossRef]

272. Wang, Z.; Yang, K.; Wang, X. Privacy-Preserving Energy Scheduling in Microgrid Systems. IEEE Trans. Smart Grid 2013, 4, 1810-1820. [CrossRef]

273. Vaccaro, A.; Loia, V.; Formato, G.; Wall, P.; Terzija, V. A Self-Organizing Architecture for Decentralized Smart Microgrids Synchronization, Control, and Monitoring. IEEE Trans. Ind. Inform. 2015, 11, 289-298. [CrossRef]

274. Xu, Y.; Li, Z. Distributed Optimal Resource Management Based on the Consensus Algorithm in a Microgrid. IEEE Trans. Ind. Electron. 2015, 62, 2584-2592. [CrossRef]

275. Sáez, D.; Ávila, F.; Olavares, D.; Cañizares, C.; Marín, L. Fuzzy Prediction Interval Models for Forecasting Renewable Resources and Loads in Microgrids. IEEE Trans. Smart Grid 2015, 6, 548-556. [CrossRef]

276. Hernández, L.; Baladrón, C.; Aguiar, J.M.; Calavia, L.; Carro, B.; Sánchez-Esguevillas, A.; Sanjuán, J.; González, A.; Lloret, J. Improved Short-Term Load Forecasting Based on Two-Stage Predictions with Artificial Neural Networks in a Microgrid Environment. Energies 2013, 6, 4489-4507. [CrossRef]

277. Hernández, L.; Baladrón, C.; Aguiar, J.M.; Carro, B.; Sánchez-Esguevillas, A.; Lloret, J. Artificial neural networks for short-term load forecasting in microgrids environment. Energy 2014, 75, 252-264. [CrossRef]

278. Ioakimidis, C.S.; Oliveira, L.J.; Genikomsakis, K.N.; Dallas, P.I. Design, architecture and implementation of a residential energy box management tool in a Smart Grid. Energy 2014, 75, 167-181. [CrossRef]

279. Amirioun, M.H.; Kazemi, A. A new model based on optimal scheduling of combined energy exchange modes for aggregation of electric vehicles in a residential complex. Energy 2014, 69, 186-198. [CrossRef]

280. Petersen, M.K.; Hansen, L.H.; Bendtsen, J.; Edlund, K.; Stoustrup, J. Heuristic Optimization for the Discrete Virtual Power Plant Dispatch Problem. IEEE Trans. Smart Grid 2014, 5, 2910-2918. [CrossRef]

281. Pandzic, H.; Kuzle, I.; Capuder, T. Virtual power plant mid-term dispatch optimization. Appl. Energy 2013, 101, 134-141. [CrossRef]

282. Bai, H.; Miao, S.; Ran, X.; Ye, C. Optimal Dispatch Strategy of a Virtual Power Plant Containing Battery Switch Stations in a Unified Electricity Market. Energies 2015, 8, 2268-2289. [CrossRef]

283. Pandzic, H.; Morales, J.M.; Conejo, A.J.; Kuzle, I. Offering model for a virtual power plant based on stochastic programming. Appl. Energy 2013, 105, 282-292. [CrossRef]

284. Gong, J.; Jiang, C.; Zhang, Y. Multiple Objective Compromised Method for Power Management in Virtual Power Plants. Energies 2011, 4, 700-716. [CrossRef]

285. Mnatsakanyan, A.; Kennedy, S.W. A Novel Demand Response Model with an Application for a Virtual Power Plant. IEEE Trans. Smart Grid 2015, 6, 230-237. [CrossRef]

286. Xyngi, I.; Popov, M. An Intelligent Algorithm for the Protection of Smart Power Systems. IEEE Trans. Smart Grid 2013, 4, 1541-1548. [CrossRef]

287. Garau, M.; Ghiani, E.; Celli, G.; Pilo, F.; Corti, S. Co-Simulation of Smart Distribution Network Fault Management and Reconfiguration with LTE Communication. Energies 2018, 11, 1332. [CrossRef]

288. Patrao, I.; Figueres, E.; Garcerá, G.; González-Medina, R. Microgrid architectures for low voltage distributed generation. Renew. Sustain. Energy Rev. 2015, 43, 415-424. [CrossRef]

289. Wang, B.; Yang, Z.; Lin, F.; Zhao, W. An Improved Genetic Algorithm for Optimal Stationary Energy Storage System Locating and Sizing. Energies 2014, 7, 6434-6458. [CrossRef]

290. Choi, J.-C.; Jeong, H.-Y.; Choi, J.-Y.; Won, D.-J.; Ahn, S.-J.; Moon, S.-I. Voltage Control Scheme with Distributed Generation and Grid Connected Converter in a DC Microgrid. Energies 2014, 7, 6477-6491. [CrossRef]

291. Ko, B.; Utomo, N.P.; Jang, G.; Kim, J.; Cho, J. Optimal Scheduling for the Complementary Energy Storage System Operation Based on Smart Metering Data in the DC Distribution System. Energies 2013, 6, 6569-6585. [CrossRef] 
292. Hwang, J.S.; Shin, W.J.; Seong, J.K.; Park, T.G.; Lee, S.H.; Lee, B.W. Experimental Design and Test of $100 \mathrm{kV}$ extra High Voltage Prototype Bushing With $\mathrm{CF}_{4}$ as Insulation Gas for Superconducting Equipment. IEEE Trans. Appl. Supercond. 2012, 22, 20-23. [CrossRef]

293. Qiao, J.; Zou, J.; Benliang, L. Calculation of the ionized field and the coronal losses of high-voltage direct current transmission lines using a finite-difference-based flux tracing method. IET Gener. Transm. Distrib. 2015, 9, 348-357. [CrossRef]

294. Arioua, L.; Marinescu, B.; Monmasson, E. Control of high voltage direct current links with overall large-scale grid objectives. IET Gener. Transm. Distrib. 2014, 8, 945-956. [CrossRef]

295. Bai, X.; Qiao, W.; Wei, H.; Huang, F.; Chen, Y. Bidirectional coordinating dispatch of large-scale V2G in a future smart grid using complementary optimization. Electr. Power Energy Syst. 2015, 68, 269-277. [CrossRef]

296. Yan, Y.; Qian, Y.; Sharif, H.; Tipper, D. A Survey on Cyber Security for Smart Grid Communications. IEEE Commun. Surv. Tutor. 2012, 14, 998-1010. [CrossRef]

297. Wang, H.; Qian, Y.; Sharif, H. Multimedia communications over cognitive radio networks for smart grid applications. IEEE Wirel. Commun. 2013, 20, 125-132. [CrossRef]

298. Zhan, T.-S.; Chen, S.-J.; Kao, C.-C.; Kuo, C.-L.; Chen, J.-L.; Lin, C.-H. Non-technical loss and power blackout detection under advanced metering infrastructure using a cooperative game based inference mechanism. IET Gener. Transm. Distrib. 2016, 10, 873-882. [CrossRef]

299. Kallitsis, M.G.; Michailidis, G.; Devetsikiotis, M. Optimal Power Allocation Under Communication Network Externalities. IEEE Trans. Smart Grid 2012, 3, 162-173. [CrossRef]

300. Ye, F.; Qian, Y.; Hu, R.Q. Energy Efficient Self-Sustaining Wireless Neighborhood Area Network Design for Smart Grid. IEEE Trans. Smart Grid 2015, 6, 220-229. [CrossRef]

301. Lv, P.; Wang, X.; Yang, Y.; Xu, M. Network Virtualization for Smart Grid Communications. IEEE Syst. J. 2014, 8, 471-482. [CrossRef]

302. Rhodes, J.D.; Upshaw, C.R.; Harris, C.B.; Meehan, C.M.; Walling, D.A.; Navrátil, P.A.; Beck, A.L.; Nagasawa, K.; Fares, R.L.; Coles, W.J.; et al. Experimental and data collection methods for a large-scale smart grid deployment: Methods and first results. Energy 2014, 65, 462-471. [CrossRef]

303. Olmos, L.; Ruester, S.; Liong, S.-J.; Glachant, J.-M. Energy efficiency actions related to the rollout of smart meters for small consumers, application to the Austrian system. Energy 2011, 36, 4396-4409. [CrossRef]

304. Lee, E.-K.; Gadh, R.; Gerla, M. Energy Service Interface: Accessing to Customer Energy Resources for Smart Grid Interoperation. IEEE J. Sel. Areas Commun. 2013, 31, 1195-1204. [CrossRef]

305. Christakou, K.; Tomozei, D.-C.; Le Boudec, J.-Y.; Paolone, M. GECN: Primary Voltage Control for Active Distribution Networks via Real-Time Demand-Response. IEEE Trans. Smart Grid 2014, 5, 622-631. [CrossRef]

306. Khojasteh, M.; Jadid, S. Decision-making framework for supplying electricity from distributed generation-owning retailers to price-sensitive customers. Util. Policy 2015, 37, 1-12. [CrossRef]

307. Mohsenian-Rad, A.-H.; Wong, V.W.S.; Jatskevich, J.; Schober, R.; Leon-Garcia, A. Autonomous Demand-Side Management Based on Game-Theoretic Energy Consumption Scheduling for the Future Smart Grid. IEEE Trans. Smart Grid 2010, 1, 320-331. [CrossRef]

308. Hirst, E. Creating Viable Utility Conservation/Load Management Programs. Energy 1988, 13, 33-44. [CrossRef]

309. Safdarian, A.; Fotuhi-Firuzabad, M.; Lehtonen, M. Integration of Price-Based Demand Response in Disco' Short-Term Decision Model. IEEE Trans. Smart Grid 2014, 5, 2235-2245. [CrossRef]

310. Sovacool, B.K. A comparative analysis of renewable electricity support mechanisms for Southeast Asia. Energy 2010, 35, 1779-1793. [CrossRef]

311. Ghazvini, M.A.F.; Faria, P.; Ramos, S.; Morais, H. Incentive-based demand response programs designed by asset-light retail electricity providers for the day-ahead market. Energy 2015, 82, 786-799. [CrossRef]

312. Gudi, N.; Wang, L.; Devabhaktuni, V. A demand side management based simulation platform incorporating heuristic optimization for management of household appliances. Int. J. Electr. Power Energy Syst. 2012, 43, 185-193. [CrossRef]

313. Wang, D.; Ge, S.; Jia, H.; Wang, C.; Zhou, Y.; Lu, N.; Kong, X. A Demand Response and Battery Storage Coordination Algorithm for Providing Microgrid Tie-Line Smoothing Services. IEEE Trans. Sustain. Energy 2014, 5, 476-486. [CrossRef]

314. Erdinc, O.; Paterakis, N.G.; Pappi, I.N.; Bakirtzis, A.G.; Catalao, J.P.S. A new perspective for sizing of distributed generation and energy storage for smart households under demand response. Appl. Energy 2015, 143, 26-37. [CrossRef] 
315. Faria, P.; Soares, T.; Vale, Z.; Morais, H. Distributed generation and demand response dispatch for a virtual power player energy and reserve provision. Renew. Energy 2014, 66, 686-695. [CrossRef]

316. Chang, T.-H.; Alizadeh, M.; Scaglione, A. Real-Time Power Balancing Via Decentralized Coordinated Home Energy Scheduling. IEEE Trans. Smart Grid 2013, 4, 1490-1504. [CrossRef] 